\title{
ARISTÓTELES, LOS SABIOS JUDÍOS Y SALOMÓN EN UNA COLECCIÓN DE SENTENCIAS INÉDITA, PALABRAS BREVES: DICHOS DE SABIOS*
}

\author{
MARTA HARO CORTÉS \\ Universitat de València
}

El proceso de creación, transmisión y pervivencia de la literatura de sentencias en la Edad Media hace de la compilatio uno de sus pilares fundamentales. La brevedad e independencia de las formas gnómicas, así como su contenido sapiencial e intemporal, que sintetiza una lección universal avalada por la autoridad de los sabios, y su perfecta disposición para ser memorizadas, favorecen la práctica compilatoria. Uno de los métodos más recurrentes, en el ámbito de la literatura de sentencias, es seleccionar, agrupar y reorganizar materiales de distinta procedencia, de acuerdo con los intereses del compilador, dando origen a un nuevo producto literario que se ajusta a las exigencias y gustos de su contexto cultural de recepción ${ }^{1}$.

\footnotetext{
* Este trabajo ha sido realizado en el marco del Proyecto de Investigación HUM2005-01334, concedido por el Ministerio de Educación y Ciencia. Quiero agradecer a Ana Marín su ayuda en la difícil trascripción de algunas sentencias de la colección, a Antonio Doñas (Universitat de València) y a César Merchán-Hamann (Oxford Center for Hebrew and Jewish Studies) su disponibilidad y su colaboración en la realización de este estudio.

${ }^{1}$ Sobre la compilatio en las colecciones de sentencias remito a Marta Haro Cortés, «Compilatio y transmisión en el Libro del consejo e de los consejeros», De la lettre à l'esprit des textes médiévaux espagnols. Hommage à Michel Garcia, ed. C. Heusch, Paris, Éditions Le Manuscrit, en prensa; José Manuel Lucía Megías, «Hacia la edición crítica de Flores de Filosofía: la collatio externa y los modelos de compilación sapiencial», Actes del VII Congrés de l'Associació Hispànica de Literatura Medieval (Castelló de la Plana, 22-26 de setembre de 1997), II, eds. Santiago Fortuño Llorens y Tomàs Martínez Romero, Castelló, Publicacions de la Universitat Jaume I, 1999, págs. 353-373; N. Hathaway, «Compilatio: From Plagiarism to Compiling», Viator, 20, 1998, págs. 19-44; A. J. Minnis, «Late-Medieval Discussions of compilatio and the Role of the compilator», Beitrtige zur Geschichte der Deutschen Sprache und Literatur, 101, 1979, págs. 385-421; M. B. Parkes, «The Influence of the Concepts of ordinatio and compilatio of the Development of the Book», Medieval Learning and Literature. Essays Presented to Richard William Hunt, eds. J. J. G. Alexander y M. T. Gibson, Oxford, Clarendon Press, 1976, págs. 115141; R. H. Rouse y M. A Rouse, «Ordinatio and compilatio Revisited», Ad litteram. Authoritative Texts and their Medieval Readers, eds. M. D. Jordan y K. Emery, Jr., Notre Dame, Uni-
} 
Este procedimiento compilatorio es el sistema de composición al que obedece Palabras breves: dichos de sabios, colección de sentencias inédita y de gran interés, que ocupa los folios $78_{\mathrm{v}}\left(\operatorname{lxxx}_{\mathrm{v}}\right)$ al $84_{\mathrm{v}}\left(\mathrm{lxxxvi}_{\mathrm{v}}\right)$ del manuscrito 5644 de la Biblioteca Nacional de Madrid; la descripción completa del códice es la siguiente:

Madrid, Biblioteca Nacional, Ms. 5644

Encuadernación en pergamino. Manuscrito en papel del siglo XV. Letra gótica cursiva. Número total de folios $112+1$ hoja de guarda. Parte del códice conserva la foliación antigua. En algunos folios aparece el nombre de Francisco de Prado y en el folio 108 se explicita que se ha escrito en Madrid. No hay presencia de ex libris ni de signaturas anteriores. La conservación del manuscrito es buena; los primeros folios desgastados en el ángulo superior derecho; no se observan manchas ni roturas.

Códice facticio. En cuanto a su contenido puede distinguirse:

- ff. $1_{\mathrm{r}}-3$ : Tabla de materias (incompleta, faltan los dos primeros folios)

- ff. 4-69: Historia de las seis edades del mundo y de los cuarenta reyes de España

- ff. 70-72 : Perfecçión poética. La infanta Calisto

- ff. $72_{\mathrm{v}}\left(\operatorname{lxxiv}_{\mathrm{v}}\right)-78_{\mathrm{v}}\left(\operatorname{lxxx}_{\mathrm{v}}\right)$ : Dichos de sabios aparte de sumas

- ff. $78_{\mathrm{v}}\left(\operatorname{lxxx}_{\mathrm{v}}\right)-84_{\mathrm{v}}\left(\mathrm{xxxvi}_{\mathrm{v}}\right)$ : Palabras breves: dichos de sabios

- ff. $84_{\mathrm{v}}\left(\operatorname{lxxxvi}_{\mathrm{v}}\right)-102_{\mathrm{r}}\left(\mathrm{ciiii}_{\mathrm{r}}\right)$ : Tratado de astronomía y cómputo

- ff. $102_{\mathrm{r}}\left(\right.$ ciiii $\left._{\mathrm{r}}\right)-107_{\mathrm{r}}\left(\right.$ cix $\left._{\mathrm{r}}\right)$ : Compendio de doctrina cristiana

- ff. $107_{\mathrm{r}}\left(\operatorname{cix}_{\mathrm{r}}\right)-112_{\mathrm{v}}\left(\right.$ cxiiii $\left._{\mathrm{v}}\right)$ : Descripción de Etiopía y Asia

La sección Palabras breves: dichos de sabios, ff. $78_{\mathrm{v}}\left(\operatorname{lxxx}_{\mathrm{v}}\right)-84_{\mathrm{v}}\left(\operatorname{lxxxvi}_{\mathrm{v}}\right)$, que es el objeto de este trabajo, presenta una tamaño total de caja de $210 \times 140$ mm. Numeración moderna a lápiz correlativa a todo el manuscrito en el ángulo inferior derecho. Además, esta parte conserva la numeración original en romanos en el ángulo superior derecho. En el folio 83(=lxxxv) el encuadernador guillotinó la numeración original que fue restituida con un trazado más grueso. En el folio $79_{\mathrm{r}}\left(\mathrm{xxxi}_{\mathrm{r}}\right)$ en el margen superior centrado, una nota de lector: «treynta yun añ ${ }^{o}$ que se hizo ellibro». En el folio $80_{\mathrm{r}}\left(\operatorname{lxxxii}_{\mathrm{r}}\right)$, la línea 20 ha sido subra-

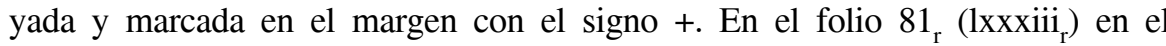
margen se observan diversas probationes calami. En el folio $82_{\mathrm{r}}$ (lxxxiiii ${ }_{\mathrm{r}}$ ) en el margen izquierdo, hacia la mitad aparece una indicación al lector en forma de mano cerrada con un dedo señalando la sentencia: «Acata en tres cosas y no

versity of Notre Dame Press, 1992, págs. 113-134; Barry Taylor, «Old Spanish Wisdom Texts: Some Relationships», La Corónica, 14, 1985, págs. 71-85 y «Medieval Proverb Collections: the West European Tradition», Journal of the Warburg and Courtauld Institutes, 55, 1992, págs. 19-35. 
vernás a pecar: entiende de qué cosa vienes, y dónde vas, y delante de quién estás aparejado de ir a juizio». Entre los folios 80 (lxxxii) y 81 (lxxxiii) se ha introducido papel $(205 \times 115 \mathrm{~mm})$ a modo de separador, posiblemente para facilitar la restauración del manuscrito. La encuadernación impide rastrear la composición de los cuadernos, así como los reclamos o signaturas si los había. El tamaño de la caja de escritura varia entre 160, 165, $170 \times 95,100,105 \mathrm{~mm}$, respectivamente; no hay puntado que permita establecer una medida uniforme para la caja. Escrito a plana corrida, entre 78 y 79 líneas por página. No hay miniaturas, ni hueco para capitales; no presenta ningún tipo de ornamentación, ni pueden distinguirse filigranas. Escrito con tinta negra y para los títulos roja.

Incipit: (rojo, centrado) If palabras breves dichos | de sabios || (negro) II el franco sienpre es honrado maguer sea pobre \|| II la cobdiçia es probre present $\left[78_{\mathrm{v}, 1-4}\left(\operatorname{lxxx}_{\mathrm{v}, 1-4}\right)\right.$

Explicit: II con el apodera miento del malo entristeze el pueblo \|| If el varon que amare saber alegra a su padre $\|$ (centro) con ilusyon [84 $\left.{ }_{\mathrm{v}, 3-5}\left(\operatorname{lxxxvi}_{\mathrm{v}, 3-5}\right)\right]$

Esta colección de sentencias, de acuerdo con su contenido, puede segmentarse en tres partes: la primera, ff. $78_{\mathrm{v}}\left(\operatorname{lxx}_{\mathrm{v}}\right)$ a $80_{\mathrm{r}}\left(\operatorname{lxxxii}_{\mathrm{r}}\right)$, que proviene del Libro de los buenos proverbios (sentencias 1-69); la segunda, ff. 80, $\left(\operatorname{lxxxii}_{\mathrm{r}}\right)$, a $83_{\mathrm{r}}\left(\operatorname{lxxxv}_{\mathrm{r}}\right)$, extraída de la Mishná judía (sentencias 75-122) y, por último, los folios $83_{\mathrm{r}}\left(\operatorname{lxxxv}_{\mathrm{r}}\right)$, a $84_{\mathrm{v}}\left(\mathrm{xxxvi}_{\mathrm{v}}\right)$ proceden de los Proverbios de Salomón (sentencias 123-156).

El Libro de los buenos proverbios es la traducción castellana del Kitãb $\tilde{a} d \tilde{b}$ al-falãsifa, compuesta en el siglo IX por Abu Zayd Hunayn ibn Ishãq (808-873), uno de los intelectuales y traductores más importantes de la corte de Bagdad del califa al-Ma'mon, a él se deben las traducciones al árabe del griego de Platón y Aristóteles ${ }^{2}$. La versión castellana se llevó a cabo durante el reinado de Alfonso X, probablemente en la segunda mitad del siglo XIII, antes de 1280, ya que en la IV parte de la General Estoria se interpolan diez capítulos referidos a Alexandre procedentes de esta obra $^{3}$.

2 Sobre Hunayn ibn Ishãq pueden consultarse los siguientes trabajos: Giuseppe Gabrieli, «Hunáyn ibn Isháq», Isis, 6, 1924, págs. 282-92; Max Meyerhof, «New Light on Hunain ibn Ishâq and his Period», Isis, 8, 1926, págs. 685-724; Manuel Alonso, «Hunayn traducido al latín por Ibn Dâwûn y Domingo Gundisalvo», Al-Andalus, 14, 1951, págs. 37-47; Hunayn ibn Ishaq. Collection d'articles publiée à l'occasion du onzième centenaire de sa mort, Arabica, 21, 1975, págs. 229-330; también la «Introducción» de Harlan Sturm a su edición The Libro de los buenos proverbios, Lexington, The University Press of Kentucky, 1971, págs. 17-20 (las referencias a la obra proceden de esta edición, así pues, sólo se indicará el número de página).

${ }^{3}$ Respecto al Libro de los buenos proverbios recomiendo la consulta de Manuel Ariza, «Diferencias textuales en los manuscritos del Libro de los buenos proverbios», Anuario de Estudios Filológicos, 5, 1982, págs. 7-16; Christy Bandak, «El Libro de los buenos proverbios a propósito de algunas diferencias textuales», Actes del X Congrés Internacional de l'Associació Hispànica de Literatura Medieval (Alacant, 18-22 de setembre de 2003), II, eds. Rafael Alemany, Josep 
Es innegable la enorme difusión del Libro de los buenos proverbios a lo largo de la Edad Media. Se han conservado cuatro testimonios todos ellos del siglo XV: L.III.2 y h.III.1, ambos de la Biblioteca del Monasterio de El Escorial (Madrid); el códice 17814 de la Biblioteca Nacional de Madrid, que comienza en el «Capítulo de un ayuntamiento de quatro filósofos que fablaron en sabençia» (cap. IV, p. 51); y el manuscrito 1763 de la Biblioteca Universitaria de Salamanca, que sólo contiene hasta el «Capítulo de las juntas de los filósofos» (cap. VI, pp. 55-61). A ellos hay que añadir un pequeño fragmento del códice 9428 de la Biblioteca Nacional de Madrid (ff. 18 $-200_{\mathrm{v}}$ ) con material del «Capítulo de las juntas de los filósofos» (cap. VI, pp. 55-61), «Capítulo de un juntamiento de siete filósofos y lo que dixo cada uno de ellos» (cap. VIII, pp. 63-64), «De un ayuntamiento de quatro filósofos» (cap. XI, p. 69), «De un enseñamiento de Sócrates, el Filósofo» (cap. XII, pp. 70-82) y de las partes finales de la obra $\mathrm{y}$, por último, la selección realizada en el códice V-6-75 (ff. $45_{\mathrm{r}}-48_{\mathrm{v}}$ ) de la Real Academia Española ${ }^{4}$. Además de estos testimonios independientes, algunas secciones del Libro de los buenos proverbios también se han transmitido insertadas en otras obras; los casos más conocidos son, por un lado, el pasaje sobre Alejandro Magno de la IV parte de la General Estoria, donde se interpolan una decena de capítulos; el del Llibre de saviesa, en el que la huella del Libro de los buenos proverbios abarca una docena de capítulos y, por otro lado, la Floresta de filósofos, tanto en los dichos 1912-2028 («Aquí comiençan algunas sentencias por algunos philósophos escritas en sus sellos e en otras partes que las ponían» — dichos 1912-1934_, «Aquí comiençan algunos dichos del sabio Platón - dichos 1935-1988-, «Ayuntamiento de siete philósophos» —dichos 1989-1995-, «Ayuntamiento de diez philósophos» —dichos 1996-2004_, «Ayuntamiento de treze philósophos»—dichos 20052017—, «Dichos de Diogenes» — dichos 2019-2026 - y «Dichos de Aristóte-

Lluís Martos, Josep Miquel Manzanaro, Alacant, Institut Interuniversitari de Filologia Valenciana, 2005, I, págs. 335-340 y «La versión castellana del Libro de los buenos proverbios», Rilce, 22.1, 2006, págs. 1-12; Marta Haro Cortés, Los compendios de castigos del siglo XIII: técnicas narrativas y contenido ético, València, Departamento de Filología Española, Universitat de València, 1995 y Literatura de castigos en la Edad Media: libros y colecciones de sentencias, Madrid, Ediciones del Laberinto, 2003, págs. 16-24; Francisco Rodríguez Adrados, Modelos griegos de la sabiduría castellana y europea. Literatura sapiencial en Grecia y la Edad Media, Madrid, Anejos del Boletín de la Real Academia Española, 2001.

${ }^{4}$ Descripción de todos los testimonios en Hugo Óscar Bizzarri, «Libro de los buenos proverbios», Diccionario Filológico de Literatura Medieval Española. Textos y transmisión, Carlos Alvar y José Manuel Lucía Megías, Madrid, Castalia, 2002, págs. 796-800. Edición de los testimonios fragmentarios por Hugo Óscar Bizzarri, «Nuevo fragmento del Libro de los buenos proverbios contenido en el manuscrito BN Madrid 9428», Incipit, 8, 1988, págs. 125-132 y por Marta Haro Cortés, «Una selección del Libro de los buenos proverbios contenido en el manuscrito V-6-75 de la Biblioteca Privada de don Antonio Rodríguez Moñino», Incipit, 15, 1995, págs. 219-235, y «El Libro de los buenos proverbios en el manuscrito 17814 de la Biblioteca Nacional de Madrid», Incipit, 25-26, 2005-2006, pp. 681-725. 
les» — dichos 2027-2028); como algunas de las sentencias agrupadas en «Prosigue Séneca vicios e virtudes» ${ }^{5}$.

También hay que mencionar la pervivencia del Libro de los buenos proverbios en el Pseudo Séneca, manuscrito escurialense S.II.13, ff. 19, $25_{\mathrm{v}}$; buena parte de los dichos recogidos en «Aquí comiençan los proverbios de Séneca llamados biçios y virtudes» pertenecen al Libro de los buenos proverbios, concretamente al «Capítulo de los proverbios que eran escritos en los sellos de los filósofos» (cap. III, pp. 48-50), a «Este es un ayuntamiento de cinco filósofos que se fablaron en sapiençia» (cap. V, pp. 53-54), «Capítulo de las juntas de los filósofos» (cap. VI, pp. 55-61), «Capítulo de un juntamiento de siete filósfos y lo que dixo cada uno d'ellos» (cap. VIII, pp. 63-64), «Este es un ayuntamientos de diez filósofos y lo que cada uno dellos dixo» (cap. IX, pp. 65-66), «Capítulo de un ayuntamiento de treze filósofos y de lo que dixieron» (cap. X, pp. 67-68), «De un ayuntamiento de quatro filósofos» (cap. XI, p. 69), «De un enseñamiento de Sócrates el filósofo» (cap. XII, pp. 70-82), «Capítulo de los castigos de Platón el sabio que dava a sus disçípulos que queríen aprender» (cap. XIII, pp. 83-92), «Capítulo del consejo que pidió Alixandre a sus maestros» (cap. XVIII, pp. 101-05) y «Capítulo de un ayuntamiento de filósofos y de lo que dixieron sobre la muerte» (cap. XXIII, pp. 116-27). Así como en el Libro de los treinta y cuatro sabios, códice escurialense a.IV.9 (ff. 1-48), o en la sección dedicada a las Enseñanzas de Pero Niño (capítulo 21) de $E l$ Victorial de Gutierre Díaz de Games ${ }^{6}$.

\footnotetext{
5 Véanse John K. Walsh, «Versiones peninsulares del Kitâb âdâb al-falâsifa de Hunayn ibn Ishâq: hacia una reconstrucción del Libro de los buenos proverbios», Al-Andalus, 41, 1976, págs. 355-84; F. Rubio, «Un texto castellano occidental de la leyenda de Alejandro Magno», Ciudad de Dios, 178, 1965, págs. 311-35 y «Las leyendas sobre Alejandro Magno en la General Estoria de Alfonso el Sabio», Ciudad de Dios, 179, 1966, págs. 431-62; George Cary, The Medieval Alexandre, Cambridge, University Press of Cambridge, 1956, reimp. 1967 y Lloyd Kasten, «Several Observations Concerning Lo libre de saviesa Attributed to James I of Aragon», Hispanic Review, 2, 1934, págs. 70-73. Por lo que se refiere a la Floresta de filósofos (las referencias provienen de la edición R. Foulché-Delbosc, «Floresta de Philosophos», Revue Hispanique, 11, 1904, págs. 5-154), remito al artículo de John K. Walsh, op. cit., y a Marta Haro Cortés, Literatura de castigos en la Edad Media: libros y colecciones de sentencias, op. cit., especialmente págs. 159-178. John. K. Walsh, op. cit., expone una documentada panorámica de la pervivencia del Libro de los buenos proverbios tanto en textos coetáneos como en obras posteriores. Dados los límites del estudio que me ocupa, remito al artículo de Walsh para las concomitancias entre el Libro de los buenos proverbios y obras como el Tratado de como al omne es nescesario amar, el Libro de las bienandanzas e fortunas de Lope García de Salazar, o los Proverbios morales de Sem Tob de Carrión, entre otras.

${ }^{6}$ Remito a Marta Haro Cortés, «Consideraciones en torno al estudio de la prosa sapiencial medieval: el caso de las colecciones de sentencias», diablotexto, 3, 1996, págs. 125-172, edición de ambos testimonios escurialenses, S.II.13, págs. 139-55 y a.IV.9, págs. 158-71. Respecto al capítulo 21 de El Victorial, véase Rafael Beltrán y Marta Haro Cortés, «Las fuentes de las enseñanzas a Pero Niño en El Victorial», Scriptura, 13, 1997, págs. 227-51.
} 
Este sucinto panorama hay que completarlo con Palabras breves: dichos de sabios que se inaugura con las sentencias recogidas en el «Capítulo de las juntas de los filósofos» (cap. VI, pp. 55-61); todas ellas atribuidas a Aristóteles, producto de las enseñanzas de Platón; sin embargo, no se hace referencia a la narración que explica la peripecia que genera la exposición de dichas formas breves ${ }^{7}$. Respecto al contenido, se ha compilado todo el material sentencioso de dicho capítulo; no obstante, aparece la sentencia: «Lo que faze la razón faze el tiempo y lo que non faze el tiempo faze la razón», que no forma parte de la obra, en lugar de «Los días fazen al omne maestro de las cosas», aquélla amplifica el sentido de ésta última.

Por lo que se refiere a la ordenación, hay que señalar que las sentencias 44 a 69 de nuestra colección en el Libro de los buenos proverbios son las que inician la sección; así pues, parece lógico suponer que el compilador, o bien se basó en una copia que presentaba esta alteración (que, por otra parte, no se observa en ninguno de los testimonios de la obra conservados); o bien, su interés se centraba en ese bloque de sentencias o pensó que, dado el espacio del que disponía, no era posible copiar todo el contenido y decidió trasladar únicamente la mitad, y luego se decidió a completar todas las sentencias del capítulo.

En relación a la labor del compilador, se observa una voluntad de síntesis que, en ningún caso, afecta al sentido de la sentencia; sirvan como ejemplo los siguientes casos: «El que no prueba su sabor non puede ser seguro que non le faga mala torpedad» (L, f. $56_{\mathrm{vb}}$ ), en nuestra colección, «Quien su saber provó, no le fará mal la torpedad» [f. $79_{\mathrm{r}}\left(\mathrm{lxxxi}_{\mathrm{r}}\right)$ ]; «Todas las cosas del mundo se pueden cambiar sinon las naturas» $\left(\mathrm{L}\right.$, f. $\left.57_{\text {ra }}\right)$, frente a «Non se pueden cambiar las cosas naturales» [f. 79 $\left.\left(\mathrm{xxxi}_{\mathrm{r}}\right)\right]$; «El que saben que es sabio todos los ojos

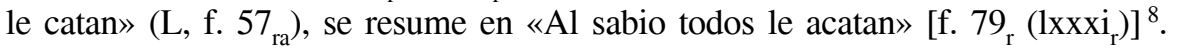

7 Resumo la anécdota: los reyes griegos querían que sus hijos aprendiesen los distintos saberes y potenciaban su interés construyendo hermosos palacios «con oro y con plata muy pintado de muchas maneras de ffiguras por tal que oviessen sabor de yr a estos palacios, ca estas eran sus escuelas» (pág. 55). Cuando alguno de los jóvenes destacaba en su aprendizaje era costumbre que asistiese a «un palaçio todo fecho de mármol entallado y ffigurado y en el día de la fiesta en que se ayuntavan todos los omnes de pro que avíe en todo el rregno en derredor daquel palacio» (pág. 55). En este acto el discípulo disertaba sobre los conocimientos adquiridos de su maestro y demostraba públicamente «de qué seso era el fijo del rey o de qué entendimiento podríe seer» (pág. 56). A continuación, se nos refiere como Nitaforios, hijo de Resusta (rey de los griegos) y discípulo de Platón, asistía a clase acompañado de su mozo Aristóteles; el hijo del rey era corto de entendimiento mientras que Aristóteles aprendía por los dos. Llegó el día de la junta, Nitaforios se vistió con ricos paños y cuando llegó el momento de mostrar su sabiduría, «non sopo fablar una palabra de cuanto avíe oydo de su maestro» (pág. 57). Platón se avergonzó tanto que para salvar su reputación preguntó si alguno de sus discípulos podía mostrar algo de lo que él les había enseñado. Aristóteles se presentó voluntario, demostró su saber y el rey «mandó fazer grant algo a Aristótiles y que fuesse su merçet» (págs. 57-58). Seguidamente, se recogen los castigos que Aristóteles aprendió de Platón.

${ }^{8}$ Otros ejemplos en las sentencias 39, 40, 58, 63, 64, 66 y 67. 
También se aprecia la combinación entre dos sentencias, fenómeno que sí repercute en el contenido y significado de las mismas: «Con el buen callar es la

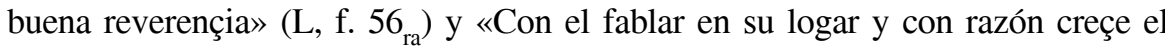
prez y enxálçase la nobleza» (L, f. 56 $6_{\mathrm{ra}}$ ), se convierte en: «Con el fablar y el callar en su lugar es la reverençia» [f. 79v ( $\left.\operatorname{xxxxi}_{\mathrm{v}}\right)$ ], el sentido se ha ampliado; pero la siguiente: «Con la razón creçe el onor y ensálçase la nobleza» [f. 79v $\left.\left(\operatorname{lxxxi}_{\mathrm{v}}\right)\right]$, sí ha modificado su mensaje ejemplar. Otro ejemplo: «Con justiçia vençe omne los enemigos» ( $\mathrm{L}, \mathrm{f} .56_{\mathrm{ra}}$ ) y «Con el sofrir creçen los ayudadores» $\left(\mathrm{L}, \mathrm{f} .56_{\mathrm{rb}}\right)$, se rehace en «Con el sofrir e la justiçia vençe omne sus enemigos» [80r (lxxxii $)$ ].

En la tabla que aporto a continuación puede seguirse la disposición de las sentencias y su ubicación en todos los testimonios del Libro de los buenos proverbios, también he incluido el Llibre de saviesa (Biblioteca Nacional de Madrid, ms. 921) y la Floresta de filósofos (Biblioteca Nacional de Madrid, ms. 4515). Las sentencias van numeradas y al final de cada una indico la página de la edición de H. Sturm. El asterisco señala la ausencia de esa sentencia en el manuscrito correspondiente.

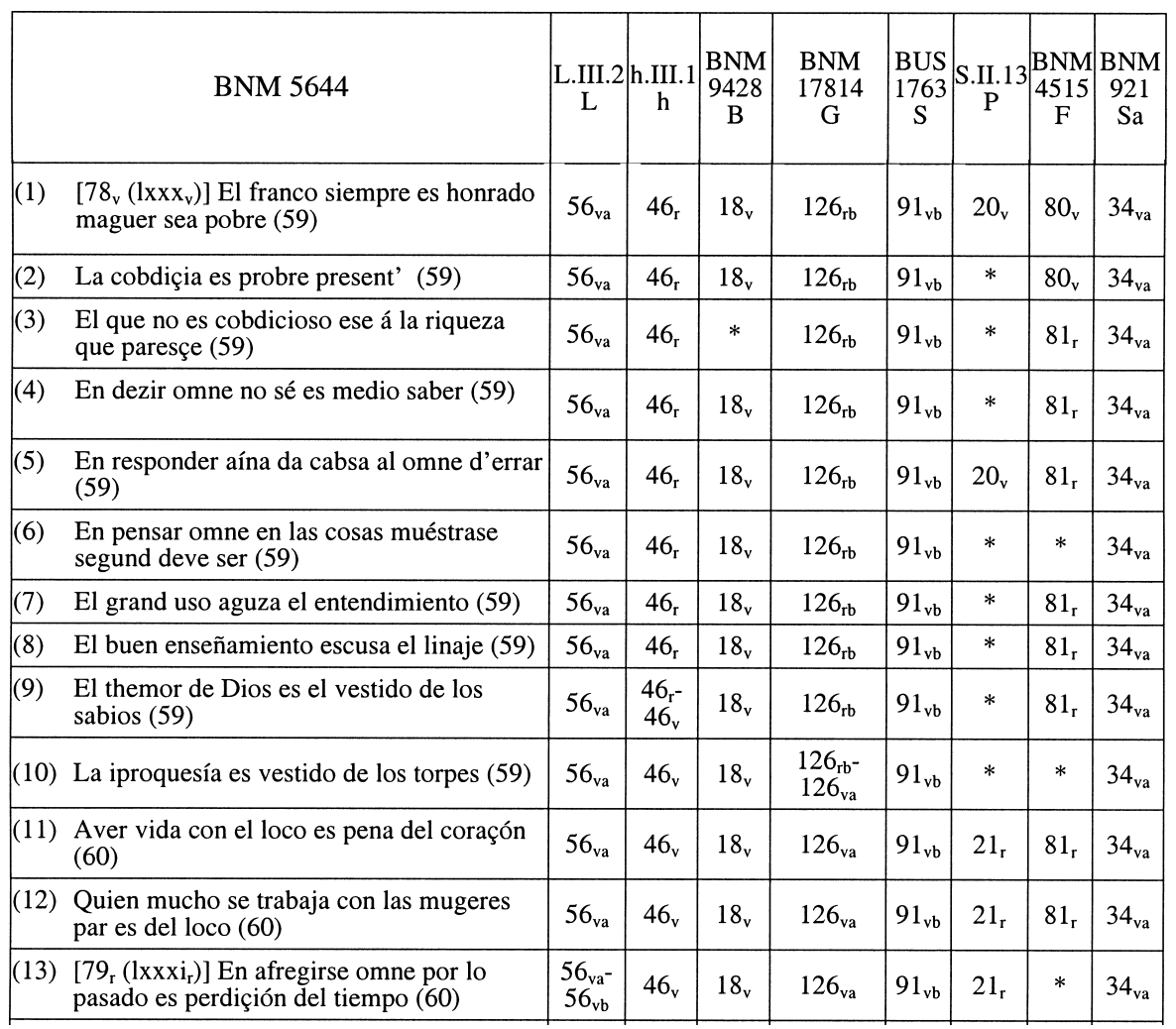




\begin{tabular}{|c|c|c|c|c|c|c|c|c|c|}
\hline & BNM 5644 & $\underset{\mathrm{L}}{\mathrm{L} . \mathrm{III} .2}$ & $\underset{\mathrm{h}}{\mathrm{h} . \mathrm{III} .1}$ & $\begin{array}{c}\text { BNM } \\
9428 \\
\text { B }\end{array}$ & $\begin{array}{c}\text { BNM } \\
17814 \\
G\end{array}$ & $\begin{array}{c}\text { BUS } \\
1763 \\
S\end{array}$ & S.II.13 & $\left|\begin{array}{c}\mathrm{BNM} \\
4515 \\
\mathrm{~F}\end{array}\right|$ & $\begin{array}{c}\text { BNM } \\
921 \\
\text { Sa }\end{array}$ \\
\hline$(14)$ & $\begin{array}{l}\text { El que se mete en los grandes peligros, } \\
\text { aventura su alma (60) }\end{array}$ & $56_{\mathrm{vb}}$ & $46_{v}$ & $18_{v}$ & $126_{\text {va }}$ & $91_{\mathrm{vb}}$ & $21_{\mathrm{r}}$ & $81_{\mathrm{r}}$ & $34_{\mathrm{va}}$ \\
\hline$(15)$ & $\begin{array}{l}\text { Por desear el omne mucho multiplica } \\
\text { mansilla (60) }\end{array}$ & $56_{\mathrm{vb}}$ & $46_{v}$ & $18 \mathrm{v}$ & $\varnothing^{9}$ & $92_{\mathrm{ra}}$ & $21_{r}$ & $81_{\mathrm{r}}$ & $34_{\text {va }}$ \\
\hline$(16)$ & $\begin{array}{l}\text { El sofrir esfuerça el ardimiento que omne } \\
\text { quiere y es fruto de consolaçión (60) }\end{array}$ & $56_{\mathrm{vb}}$ & $46_{v}$ & $18 \mathrm{v}$ & $\varnothing$ & $92_{\mathrm{ra}}$ & $21_{\mathrm{r}}$ & $81_{r}$ & $34_{\mathrm{va}}$ \\
\hline$(17)$ & El amigo del torpe bive engañado (60) & $56_{\mathrm{vb}}$ & $46_{v}$ & $18_{\mathrm{v}}$ & $\varnothing$ & $92_{\mathrm{ra}}$ & $21_{r}$ & $81_{\mathrm{r}}$ & $34_{\text {va }}$ \\
\hline$(18)$ & $\begin{array}{l}\text { El que se mete en aventuras a las vezes } \\
\text { desfallesçe }(60)\end{array}$ & $56_{\mathrm{vb}}$ & $46_{v}$ & $18_{v}$ & $\varnothing$ & $92_{\text {ra }}$ & $21_{\mathrm{r}}$ & $*$ & $34_{\mathrm{va}}$ \\
\hline (19) & $\begin{array}{l}\text { El que se conosçe non se pierde ant' los } \\
\text { omnes }(60)\end{array}$ & $56_{\mathrm{vb}}$ & $46_{v}$ & $18_{\mathrm{v}}$ & $\varnothing$ & $92_{\text {ra }}$ & $21_{\mathrm{r}}$ & $81_{\mathrm{r}}$ & $34_{\mathrm{vb}}$ \\
\hline$(20)$ & $\begin{array}{l}\text { El que es más su saber que su seso es } \\
\text { dañamiento d'él (60) }\end{array}$ & $56_{\mathrm{vb}}$ & $46_{v}$ & $*$ & $\varnothing$ & $92_{\text {ra }}$ & $21_{\mathrm{r}}$ & $81_{\mathrm{r}}$ & $34_{\mathrm{vb}}$ \\
\hline$(21)$ & $\begin{array}{l}\text { El provador es más sabidor que el físico } \\
(60)\end{array}$ & $56_{\mathrm{vb}}$ & $46_{v}$ & $*$ & $\varnothing$ & $92_{\text {ra }}$ & $21_{\mathrm{r}}$ & $81_{r}$ & $34_{\mathrm{vb}}$ \\
\hline$(22)$ & Quando fueres ensañado, cállate (60) & $56_{\mathrm{vb}}$ & $46_{v}$ & $18_{\mathrm{v}}$ & $\varnothing$ & $92_{\mathrm{ra}}$ & $21_{r}$ & $81_{\mathrm{r}}$ & $34_{\mathrm{vb}}$ \\
\hline$(23)$ & $\begin{array}{l}\text { Quien su saber provó, no le fará mal la } \\
\text { torpedad }(60)\end{array}$ & $56_{\mathrm{vb}}$ & $46_{v}$ & $\begin{array}{c}18_{\mathrm{v}^{-}}^{-} \\
19_{\mathrm{r}}\end{array}$ & $\varnothing$ & $92_{\text {ra }}$ & $21_{\mathrm{r}}$ & $*$ & $34_{\mathrm{vb}}$ \\
\hline$(24)$ & Quien se esfuerça no se arrepiente (60) & $56_{\mathrm{vb}}$ & $46_{v}$ & $19_{\mathrm{r}}$ & $\varnothing$ & $92_{\mathrm{ra}}$ & $21_{\mathrm{r}}$ & $81_{r}$ & $34_{\mathrm{vb}}$ \\
\hline$(25)$ & $\begin{array}{l}\text { Quien se aventuró, vídose en grand afrenta } \\
(60)\end{array}$ & \begin{tabular}{|l}
$56_{\mathrm{vb}^{-}}$ \\
$57_{\mathrm{ra}}$ \\
\end{tabular} & $46_{v}$ & $19_{\mathrm{r}}$ & $\varnothing$ & $92_{\text {ra }}$ & $21_{\mathrm{r}}$ & $81_{r}$ & $34_{\mathrm{vb}}$ \\
\hline (26) & $\begin{array}{l}\text { Quien se apresura más que no debe, } \\
\text { engáñase (60) }\end{array}$ & $57_{\text {ra }}$ & $46_{v}$ & $19_{\mathrm{r}}$ & $\varnothing$ & $92_{\mathrm{ra}}$ & $21_{r}$ & $81_{r}$ & $34_{\mathrm{vb}}$ \\
\hline$(27)$ & El que pensó, estorçió (60) & $57_{\mathrm{ra}}$ & $46_{v}$ & $19_{\mathrm{r}}$ & $\varnothing$ & $92_{\mathrm{ra}}$ & $21_{\mathrm{r}}$ & $81_{\mathrm{r}}$ & $34_{\mathrm{vb}}$ \\
\hline$(28)$ & El que preguntó, aprendió (60) & $57_{\mathrm{ra}}$ & $46_{v}$ & $19_{\mathrm{r}}$ & $\varnothing$ & $92_{\mathrm{ra}}$ & $21_{r}$ & $81_{r}$ & $34_{\mathrm{vb}}$ \\
\hline$(29)$ & $\begin{array}{l}\text { El que quiso levar lo que non pudo, } \\
\text { embargose (60) }\end{array}$ & $57_{\text {ra }}$ & $46_{v}$ & $19_{\mathrm{r}}$ & $\varnothing$ & $92_{\text {ra }}$ & $21_{\mathrm{r}}$ & $*$ & $34_{\mathrm{vb}}$ \\
\hline$(30)$ & Las pruevas no han fin $(60)$ & $57_{\mathrm{ra}}$ & $46_{v}$ & $19 \mathrm{r}$ & $\varnothing$ & $92_{\text {ra }}$ & $21_{\mathrm{r}}$ & $81_{\mathrm{r}}$ & $34_{\mathrm{vb}}$ \\
\hline$(31)$ & $\begin{array}{l}\text { El sesudo siempre añade en las pruevas } \\
(60)\end{array}$ & $57_{\text {ra }}$ & $46_{v}$ & $*$ & $\varnothing$ & $92_{\text {ra }}$ & $21_{r}$ & $81_{\mathrm{r}}$ & $34_{\mathrm{vb}}$ \\
\hline$(32)$ & El uso es rey sobre todas las cosas (60) & $57_{\mathrm{ra}}$ & $46_{v}$ & $19_{\mathrm{r}}$ & $\varnothing$ & $92_{\mathrm{ra}}$ & $21_{\mathrm{r}}$ & $81_{r}$ & $34_{\mathrm{vb}}$ \\
\hline$(33)$ & $\begin{array}{l}\text { Non se pueden cambiar las cosas naturales } \\
(60)\end{array}$ & $57_{\mathrm{ra}}$ & $46_{v}$ & $19_{\mathrm{r}}$ & $\varnothing$ & $92_{\mathrm{rb}}$ & $21_{\mathrm{r}}$ & $*$ & $34_{\mathrm{vb}}$ \\
\hline$(34)$ & $\begin{array}{l}\text { En todas las cosas puede aver arte salvo en } \\
\text { el juizio }\end{array}$ & $57_{\text {ra }}$ & $46_{v}$ & $19_{\mathrm{r}}$ & $\varnothing$ & $92_{\mathrm{rb}}$ & * & $*$ & $34_{\mathrm{vb}}$ \\
\hline$(35)$ & Al sabio todos le acatan & $57_{\mathrm{ra}}$ & $46_{v}$ & $19 \mathrm{r}$ & $\varnothing$ & $92_{\mathrm{rb}}$ & $*$ & $81_{v}$ & $34_{\mathrm{vb}}$ \\
\hline$(36)$ & $\begin{array}{l}\text { Con el seso y sosegamiento cumple omne } \\
\text { maguer [non } s . l \text { ] sea razonado }(61)\end{array}$ & $57_{\mathrm{ra}}$ & $46_{v}$ & $19_{r}$ & $\varnothing$ & $92_{\mathrm{rb}}$ & $*$ & $81_{v}$ & $34_{\mathrm{vb}}$ \\
\hline$(37)$ & $\begin{array}{l}\text { El abreviamiento segura al dezidor del mal } \\
\text { entendimiento del oidor }(61)\end{array}$ & $57_{\mathrm{ra}}$ & $46_{v}$ & $*$ & $\varnothing$ & $92_{\mathrm{rb}}$ & $21_{r}$ & $81_{v}$ & $34_{\mathrm{vb}}$ \\
\hline
\end{tabular}

${ }^{9}$ En G más de la mitad de la segunda columna del folio $126_{\mathrm{v}}$ y todo el 127 en blanco. 


\begin{tabular}{|c|c|c|c|c|c|c|c|c|c|}
\hline & BNM 5644 & $\underset{\mathrm{L}}{\mathrm{L} . \mathrm{III} .2}$ & $\underset{\mathrm{h}}{\mathrm{h} . \mathrm{III} .1}$ & $\begin{array}{c}\text { BNM } \\
9428 \\
\text { B }\end{array}$ & $\begin{array}{l}\text { BNM } \\
17814 \\
\text { G }\end{array}$ & $\begin{array}{c}\text { BUS } \\
1763 \\
S\end{array}$ & S.II.13 & $\begin{array}{c}\mathrm{BNM} \\
4515 \\
\mathrm{~F}\end{array}$ & $\begin{array}{c}\text { BNM } \\
921 \\
\mathrm{Sa}\end{array}$ \\
\hline$(38)$ & $\begin{array}{l}{\left[79_{\mathrm{v}}\left(\mathrm{l} \times \mathrm{xxi} \mathrm{i}_{\mathrm{v}}\right)\right] \text { Fallada la fin de la verdad }} \\
\text { escusan mucho preguntar, y quien no falló } \\
\text { la fin de la verdad estuvo afondado en la } \\
\text { torpedad, y arredrado con el sabor de la } \\
\text { puerta del embargamiento, y tollido con el } \\
\text { mal uso de presçiar el aprender }(61)\end{array}$ & $57_{\mathrm{rb}}$ & $46_{v}$ & $19 \mathrm{r}$ & $\varnothing$ & $92_{\mathrm{rb}}$ & $21_{\mathrm{r}}$ & $81_{v}$ & $34_{\mathrm{vb}}$ \\
\hline (39) & $\begin{array}{l}\text { Quien se cuita por las cuitas de su amigo es } \\
\text { más loado que darse a espaçio (61) }\end{array}$ & $57_{\mathrm{rb}}$ & $46_{v}$ & $19 \mathrm{r}$ & $\varnothing$ & $92_{\mathrm{rb}}$ & $21_{r}$ & $*$ & $34_{\mathrm{vb}}$ \\
\hline$(40)$ & $\begin{array}{l}\text { En sofrir omne sus cuitas es más loado que } \\
\text { quien se quexase (60) }\end{array}$ & $57_{\mathrm{rb}}$ & $46_{v}$ & $19_{\mathrm{r}}$ & $\varnothing$ & $92_{\mathrm{rb}}$ & $21_{r}$ & $81_{v}$ & $35_{\mathrm{ra}}$ \\
\hline$(41)$ & $\begin{array}{l}\text { Non ha cosa por que tanto se pierda el bien } \\
\text { y la merçed como por durar el mal fazer } \\
\text { (61) }\end{array}$ & $57_{\mathrm{rb}}$ & $\begin{array}{l}46_{v^{-}} \\
47_{r}\end{array}$ & $19_{\mathrm{r}}$ & $\varnothing$ & $92_{\mathrm{rb}}$ & $21_{\mathrm{v}}$ & $*$ & $35_{\mathrm{ra}}$ \\
\hline$(42)$ & $\begin{array}{l}\text { Quien quiere servir al rey sin buen } \\
\text { enseñamiento sale de la salud a la muerte } \\
\text { (61) }\end{array}$ & $57_{\mathrm{rb}}$ & $47_{\mathrm{r}}$ & $*$ & $\varnothing$ & $92_{\mathrm{rb}}$ & $21_{\mathrm{v}}$ & $81_{v}$ & $35_{\mathrm{ra}}$ \\
\hline (43) & $\begin{array}{l}\text { El sofrir al señorío es grave y desçender a } \\
\text { la aviltança es rafez (61) }\end{array}$ & $57_{\mathrm{rb}}$ & $47_{\mathrm{r}}$ & $19_{\mathrm{r}}$ & $\varnothing$ & $92_{\mathrm{rb}}$ & $21_{\mathrm{v}}$ & $81_{v}$ & $35_{\mathrm{ra}}$ \\
\hline (44) & $\begin{array}{l}\text { Con el pensamiento agudo se alcança } \\
\text { consejo a las cosas graves }(58)\end{array}$ & $\begin{array}{l}55_{\mathrm{vb}^{-}} \\
56_{\mathrm{ra}}\end{array}$ & $46_{r}$ & $18_{\mathrm{r}}$ & $126_{\mathrm{ra}}$ & $91_{\mathrm{rb}}$ & $*$ & $80_{\mathrm{r}}$ & $34_{\mathrm{rb}}$ \\
\hline (45) & $\begin{array}{l}\text { Mansamente puede omne aver las cosas } \\
\text { mejor que las demanda (58) }\end{array}$ & $56_{\mathrm{ra}}$ & $46_{r}$ & $18_{\mathrm{r}}$ & $126_{\mathrm{ra}}$ & $91_{\mathrm{rb}}$ & * & $80_{\mathrm{r}}$ & $*^{10}$ \\
\hline$(46)$ & $\begin{array}{l}\text { Con la palabra blanda dura el amor en los } \\
\text { coraçones (58) }\end{array}$ & $56_{\mathrm{ra}}$ & $46_{r}$ & $18_{\mathrm{r}}$ & $126_{\mathrm{ra}}$ & $91_{\mathrm{rb}}$ & $20_{\mathrm{v}}$ & $80_{\mathrm{r}}$ & $34_{\mathrm{rb}}$ \\
\hline (47) & $\begin{array}{l}\text { En la omildad se acaban todas las cosas } \\
\text { (58) }\end{array}$ & $56_{\mathrm{ra}}$ & $46_{r}$ & $18_{\mathrm{r}}$ & $126_{\mathrm{ra}}$ & $91_{\mathrm{rb}}$ & $20_{v}$ & $80_{\mathrm{r}}$ & $34_{\mathrm{rb}}$ \\
\hline$(48)$ & $\begin{array}{l}\text { En el espaçio de la voluntad es la vida } \\
\text { sabrosa y cúmplese el alegría (58) }\end{array}$ & $56_{\text {ra }}$ & $46_{r}$ & $18_{\mathrm{r}}$ & $126_{\mathrm{ra}}$ & $91_{\mathrm{rb}}$ & $20_{v}$ & $80_{v}$ & $34_{\mathrm{rb}}$ \\
\hline (49) & $\begin{array}{l}\text { Con el fablar y el callar en su lugar es la } \\
\text { reverençia (58) }\end{array}$ & $56_{\mathrm{ra}}$ & $46_{r}$ & $18_{\mathrm{r}}$ & $126_{\mathrm{ra}}$ & $91_{\mathrm{rb}}$ & $20_{v}$ & $80_{v}$ & $34_{\mathrm{rb}}$ \\
\hline$(50)$ & $\begin{array}{l}\text { Con la razón creçe el onor y ensálçase la } \\
\text { nobleza (58) }\end{array}$ & $56_{\mathrm{ra}}$ & $46_{r}$ & $18_{r}$ & $126_{\mathrm{ra}}$ & $\begin{array}{l}91_{\mathrm{rb}^{-}} \\
91_{\mathrm{va}}\end{array}$ & $20_{v}$ & $80_{v}$ & $34_{\mathrm{rb}}$ \\
\hline$(51)$ & Con la mesura es la amistad (58) & $56_{\mathrm{ra}}$ & $46_{r}$ & $18_{\mathrm{r}}$ & $126_{\mathrm{ra}}$ & $91_{\mathrm{va}}$ & $20_{\mathrm{v}}$ & $80_{v}$ & $34_{\mathrm{rb}}$ \\
\hline$(52)$ & Con omildad cresçe el amor (58) & $56_{\mathrm{ra}}$ & $46_{\mathrm{r}}$ & $18_{\mathrm{r}}$ & $126_{\mathrm{ra}}$ & $91_{\mathrm{va}}$ & $20_{\mathrm{v}}$ & $*$ & $34_{\mathrm{rb}}$ \\
\hline$(53)$ & Con la castidad son los buenos fechos (58) & $56_{\mathrm{ra}}$ & $46_{r}$ & $18_{\mathrm{v}}$ & $126_{\mathrm{ra}}$ & $91_{\mathrm{va}}$ & $*$ & $80_{v}$ & $34_{\mathrm{rb}}$ \\
\hline$(54)$ & Con el bien fazer es el señorío (59) & $56_{\mathrm{ra}}$ & $46_{r}$ & $18_{\mathrm{v}}$ & $126_{\mathrm{ra}} 126_{\mathrm{rb}}$ & $91_{\mathrm{va}}$ & $20_{\mathrm{v}}$ & $80_{v}$ & $34_{\mathrm{rb}}$ \\
\hline$(55)$ & 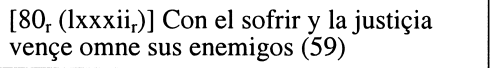 & $56_{\mathrm{ra}}$ & $46_{\mathrm{r}}$ & $18 \mathrm{v}$ & $126_{\mathrm{rb}}$ & $91_{\mathrm{va}}$ & $20_{\mathrm{v}}$ & $80_{v}$ & $34_{\mathrm{rb}}$ \\
\hline (56) & $\begin{array}{l}\text { Con la mansedumbre se sirve onme de los } \\
\text { coraçones (59) }\end{array}$ & $56_{\mathrm{rb}}$ & $46_{r}$ & $18_{\mathrm{v}}$ & $126_{\mathrm{rb}}$ & $91_{\mathrm{va}}$ & $20_{v}$ & $80_{v}$ & $34_{\mathrm{rb}}$ \\
\hline (57) & $\begin{array}{l}\text { Por el honramiento se gana nombradía de } \\
\text { bondad (59) }\end{array}$ & $56_{\mathrm{rb}}$ & $46_{r}$ & $18_{v}$ & $126_{\mathrm{rb}}$ & $91_{\mathrm{va}}$ & $20_{\mathrm{v}}$ & $80_{v}$ & $34_{\mathrm{rb}}$ \\
\hline
\end{tabular}

${ }^{10}$ Esta sentencia no aparece en el manuscrito 921 de la Biblioteca Nacional de Madrid (que hemos tomado como referencia), pero sí en el códice escurialense M.I.29, f. $4_{\text {r. }}$. 


\begin{tabular}{|c|c|c|c|c|c|c|c|c|c|}
\hline & BNM 5644 & $\stackrel{\text { L.III. } 2}{\mathrm{~L}}$ & $\underset{\mathrm{h}}{\mathrm{h} . \mathrm{III} .1}$ & $\begin{array}{c}\text { BNM } \\
9428 \\
\text { B }\end{array}$ & $\begin{array}{l}\text { BNM } \\
17814 \\
\text { G }\end{array}$ & $\begin{array}{l}\text { BUS } \\
1763 \\
\text { S }\end{array}$ & S.II.13 & $\begin{array}{c}\mathrm{BNM} \\
4515 \\
\mathrm{~F}\end{array}$ & $\begin{array}{l}\text { BNM } \\
921 \\
\mathrm{Sa}\end{array}$ \\
\hline$(58)$ & $\begin{array}{l}\text { Quien faze bien y merçed gana suma } \\
\text { granada (59) }\end{array}$ & $56_{\mathrm{rb}}$ & $46_{r}$ & $*$ & * & $91_{\mathrm{va}}$ & $20_{\mathrm{v}}$ & $80_{v}$ & $34_{\mathrm{rb}}$ \\
\hline$(59)$ & Con la lealtad dura la hermandat (59) & $56_{\mathrm{rb}}$ & $46_{r}$ & $18_{\mathrm{v}}$ & $*$ & $91_{\mathrm{va}}$ & $20_{v}$ & $80_{v}$ & $34_{\mathrm{rb}}$ \\
\hline$(60)$ & Con la verdad cresçe la bondad (59) & $56_{\mathrm{rb}}$ & $46_{r}$ & $18_{v}$ & $*$ & $91_{\mathrm{va}}$ & $20_{\mathrm{v}}$ & $80_{\mathrm{v}}$ & $34_{\mathrm{rb}}$ \\
\hline$(61)$ & $\begin{array}{l}\text { Quien bien mira las cosas alegará buenos } \\
\text { enxemplos (59) }\end{array}$ & $56_{\mathrm{rb}}$ & $46_{r}$ & $18_{\mathrm{v}}$ & $126_{\mathrm{rb}}$ & $91_{\mathrm{va}}$ & $*$ & $80_{v}$ & $34_{\mathrm{rb}}$ \\
\hline$(62)$ & $\begin{array}{l}\text { Lo que non faze la razón faze el tiempo, y } \\
\text { lo que non faze el tiempo faze la razón (59) }\end{array}$ & - & - & - & - & - & - & - & - \\
\hline$(63)$ & $\begin{array}{l}\text { Quien bien sabe las cosas puja en su } \\
\text { bondad (59) }\end{array}$ & $56_{\mathrm{rb}}$ & $46_{r}$ & $18_{\mathrm{v}}$ & $126_{\mathrm{rb}}$ & $91_{\mathrm{va}}$ & $20_{\mathrm{v}}$ & $*$ & $34_{\mathrm{rb}}$ \\
\hline (64) & $\begin{array}{l}\text { El sabor del comer y del bever es en la } \\
\text { salud (59) }\end{array}$ & $56_{\mathrm{rb}}$ & $46_{r}$ & $18_{\mathrm{v}}$ & $126_{\mathrm{rb}}$ & $91_{\mathrm{va}}$ & $20_{\mathrm{v}}$ & $80_{v}$ & $34_{\mathrm{rb}}$ \\
\hline$(65)$ & $\begin{array}{l}\text { Con las cuitas es la mala vida y túrbanse } \\
\text { los otros bienes (59) }\end{array}$ & $56_{\mathrm{rb}}$ & $46_{r}$ & $18_{\mathrm{v}}$ & $126_{\mathrm{rb}}$ & $91_{\mathrm{va}}$ & $20_{v}$ & $*$ & $34_{\mathrm{rb}}$ \\
\hline (66) & $\begin{array}{l}\text { Por negar el bien y la merçed se pierde el } \\
\text { bien fazer (59) }\end{array}$ & $56_{\mathrm{rb}}$ & $46_{r}$ & $18_{\mathrm{v}}$ & $126_{\mathrm{rb}}$ & $91_{\mathrm{va}}$ & $*$ & $*$ & $34_{\mathrm{rb}}$ \\
\hline (67) & $\begin{array}{l}\text { Quien se aína enoja su amistad poco tura } \\
\text { (59) }\end{array}$ & $56_{\mathrm{rb}}$ & $46_{r}$ & $18 v$ & $126_{\mathrm{rb}}$ & $91_{\mathrm{va}}$ & $*$ & $80_{v}$ & $34_{\mathrm{va}}$ \\
\hline (68) & $\begin{array}{l}\text { El omne sañudo peligro es de su compañía } \\
\text { (59) }\end{array}$ & $56_{\mathrm{va}}$ & $46_{r}$ & $18_{v}$ & $126_{\mathrm{rb}}$ & $91_{\mathrm{vb}}$ & $20_{\mathrm{v}}$ & $*$ & $34_{\text {va }}$ \\
\hline (69) & $\begin{array}{l}\text { El escaso siempre es abiltado maguer sea } \\
\text { rico (59) }\end{array}$ & $56_{\mathrm{va}}$ & $46_{r}$ & $18_{v}$ & $126_{\mathrm{rb}}$ & $91_{\mathrm{vb}}$ & $20_{v}$ & $80_{v}$ & $34_{\mathrm{va}}$ \\
\hline
\end{tabular}

El segundo bloque de sentencias, de la 75 a la 122, deriva de la Mishná judía. La Mishná, junto con el Talmud y el Midrásh, componen la Ley Oral que fue entregada a Moisés junto con la Ley Escrita o Torá. La Ley Oral fue transmitida por Moisés a Josué y, de este modo, fue memorizada y transmitida hasta que en el siglo segundo, aproximadamente, fue codificada por el Patriarca Judá. El Midrásh es un corpus de comentarios, análisis y distintas interpretaciones de la Biblia hebrea. El Talmud con sus dos redacciones, la de Babilonia (el 'Talmud Bavli') y la de Jerusalén ('Talmud Ierushalmi'), recoge las discusiones de los rabinos sobre los puntos oscuros o dudosos de la Ley Oral, tal y como se habían presentado en la Mishná. Así las cosas, el Talmud se divide en dos partes: la Mishná, esto es, las leyes judías y la Guemará, posterior a la Mishná, centrada en el comentario y análisis de estas leyes.

La Mishná se divide en seis órdenes ('sedarim'): preceptos relacionados con el trabajo de la tierra (Zeraim), con las fiestas (Mo'ed), con las mujeres y la vida matrimonial (Nashim), referentes a la vida civil y al comercio (Nezikin),

${ }^{11}$ Esta sentencia no se encuentra en el Libro de los buenos proverbios, en su lugar y relacionada por lo que se refiere al sentido: «Los días fazen al omne maestro de las cosas». 
leyes religiosas del templo y su funcionamiento (Kodashim) y consideraciones relacionadas con la purificación del cuerpo (Tohorot). El cuarto orden, centrado en las leyes civiles, también contiene el único tratado de contenido no legal, sino sapiencial, es el llamado Pirqué Abot o Abot ('Capítulo de los padres'), que transmite enseñanzas éticas y de filosofía judía de los sabios maestros ${ }^{12}$.

La segunda parte de Palabras breves: dichos de sabios procede del Pirqué Abot, en concreto de los cuatro primeros capítulos. El compilador, como norma general, no menciona a quien se atribuye la sentencia, cuando sí consta en todas las secciones del tratado que toma como fuente y, del mismo modo, pasa por alto las referencias a la Torá, a excepción de la sentencia 104 («Trabaja siempre de aprender la Ley por que sepas responder al que es hereje»). Sirvan como muestra los siguientes ejemplos (la cursiva es mía):

Siempre sed de aquellos que aman la paz e andan en ella [80 $\left.\left(1 \mathrm{xxxii}_{\mathrm{v}}\right)\right]$

Hilel y Samay la recibieron de ellos. Hilel solía decir: sé un discípulo de Aarón, ama y busca la paz, ama a los otros hombres y acércalos a la Torá ${ }^{13}$

$\mathrm{Si}$ fueres bueno e guardares la fee no digas que as fecho mucho porque para esto eres criado $\left[81_{\mathrm{v}}\left(\operatorname{lxxxiii_{\mathrm {v}})}\right]\right.$

Rabán Yojanán, hijo de Zakay, la recibió de Hilel y de Samay. Solía decir: si estudiaste mucha Torá, no te lo tomes como mérito, porque para eso fuiste creado. Rabán Yojanán, hijo de Zakay, tuvo cinco discípulos: Rabí Eliezer, hijo de Hircanos; Rabí Josué, hijo de Ananías, Rabí Yosé, el sacerdote; Rabí Simón, hijo de Natanael y Rabí Elazar, hijo de Araj. Resaltaba frecuentemente sus cualidades. $R$. Eliezer, hijo de Hircanos, es una cisterna encalada que no pierde una gota de agua; $R$. Josué, ifeliz la que le dio el ser!; $R$. Yosé es un hombre piadoso; R. Simón, hijo de Natanael, es temeroso del pecado; R. Elazar, hijo de Araj, es una fuente que crece constantemente. Acostumbraba a decir: si todos los sabios de Israel estuvieran en el platillo de la balanza y Eliezer, hijo de Hircanos, en el otro platillo, inclinaría a su lado el platillo de la balanza. Abá Saúl decía en su nombre: si todos los sabios de Israel estuvieren en el platillo de la balanza, acompañándoles $R$ Eliezer, hijo de Hircanos, y en el otro platillo estuviere R. Eleazar, éste contrabalancearía a todos los otros (pp. 792-793, 8).

Es más, cuando en el Pirqué Abot la piedra angular del versículo es la Torá, o se citan varios pasajes de la Biblia, dicho segmento sentencioso no es recogido. El segundo capítulo del Pirqué Abot se divide en dieciséis secciones, en nuestra colección se recogen sistemáticamente todas hasta la catorce, el único salto de contenido es la número trece:

12 El tratado Abot consta de cinco capítulos de Mishná; no obstante, cuando se habla de Pirqué Abot se hace referencia a seis, los cinco del Abot más otro que pertenece a la Baraitá, es decir, aquellas enseñanzas de los sabios que no se introdujeron en la Mishná.

13 Todas las citas de la Mishná proceden de la edición de Carlos del Valle, Misná, Madrid, Editora Nacional, 1981; cita pág. 790, 12; únicamente se indicará el número de página y la sección. 
R. Simón decía: ten cuidado en la recitación del shema y de la oración. Cuando ores, no hagas de tu oración algo rutinario, sino que ha de ser un acto (de petición) de clemencia y gracia a Dios, bendito sea, como está escrito: 'porque es un Dios clemente y misericordioso, paciente y magnánimo, que se arrepiente del mal' ${ }^{14}$. No te hagas prevaricador ante ti mismo (pp. 794-795, 13).

La última sección de Palabras breves: dichos de sabios (sentencias 123156) proviene de los Provebios de Salomón (capítulos 25 a 29), uno de los libros sapienciales bíblicos de mayor circulación que en la tradición judía forma parte de la Ley escrita. El Tanaj o Biblia hebrea se compone de tres partes: la Torá, los cinco primeros libros de la Biblia o Pentateuco que son la base de la religión judía; los Nevi'im, libros de los Profetas y los Ketuvim o escritos ${ }^{15}$. Los Proverbios de Salomón se incluyen en esta última parte junto con otros libros sapienciales como el Libro de Job o el Eclesiastés.

El hecho de que los castigos de Aristóteles provengan del Libro de los buenos proverbios no nos aleja del contexto cultural judío. Esta obra fue traducida del árabe al hebreo (Musrei ha-Filosofim) por Yehudá al-Harizi (1170-1230), uno de los poetas y traductores judío sefardí más importantes de la Edad Media, que viajó a Oriente, Jerusalén y residió en Toledo; su composición más importante es el Séfer Tajkemoni, una de las obras fundamentales de la narrativa hispanohebrea; además también se debe a su pericia la traducción al hebreo bíblico de la Guía de perplejos de Maimónides (uno de los textos que más influyó en el debate judío entre la fe y la filosofía) ${ }^{16}$. Así pues, a partir del siglo

\footnotetext{
14 Joel 2, 13.
}

${ }^{15}$ El Tanaj se divide en tres partes: la Torá que comprende los cinco primeros libros de la Biblia: Génesis, Éxodo, Levítico, Números y Deuteronomio. Los Nevi'im o 'Profetas' que agrupan los libros de Josué, Jueces, Samuel (I y II), Reyes (I y II), Isaías, Jeremías, Ezequiel y los doce profetas menores (Oseas, Joel, Amós, Abdías, Jonás, Miqueas, Najum, Habacuc, Sofoías, Ageo, Zacarías y Malaquías). Y los Ketuvim o 'Escritos' que recogen libros poéticos (Salmos, Lamentaciones, Cantar de los Cantares), históricos (Rut, Crónicas I y II, Ester, Esdras y Nehemías), sapienciales (Proverbios, Job y Eclesiastés) y el Libro de Daniel.

16 Sobre al-Harizi remito a Ángel Saenz-Badillos y Judit Targarona Borrás, Diccionario de Autores Judíos (Sefarad. Siglos X-XV), Córdoba, Ediciones el Almendro, 1988, págs. 133-134; Ángel Saenz-Badillos, Literatura Hebrea en la España Medieval, Madrid, Fundación Amigos de Safarad, Universidad Nacional de Educación a Distancia, 1991, págs. 205-206 y «Yehudah alHarizi, admirador de Maimónides», MEAH: Miscelánea de Estudios Árabes y Hebraicos. Sección Hebrero, 34.2, 1985, págs. 61-70; Joseph Sadan, «Un intellectuel juif au confluent de deux cultures: Yehuda al-Harizi et sa biographie arabe», Judíos y musulmanes en Al-Andalus y el Magreb: contactos intelectuales, ed. Maribel Fierro, Madrid, Casa de Velázquez, 2002, págs. 105151; A.A.P. Lavin, «Judah al-Harizi: la conexión judío-árabe inesperada», Romance Notes, 39.1, 1998, págs. 9-14; Ángeles Navarro Peiró, Literatura hispanohebrea, Madrid, Ediciones del Laberinto, 2006, especialmente págs. 148-151. Su obra Séfer Tajkemoni puede consultarse en traducción castellana en Judá ben Shelomoh al-Harizi, Las asambleas de los sabios (Tahkemoni), ed. Carlos del Valle, Murcia, Universidad de Murcia, 1988. 
XIII convivieron la versión castellana y la hebrea del Libro de los buenos proverbios ${ }^{17}$.

No cabe duda de que Palabras breves: dichos de sabios, teniendo en cuenta todo lo que antecede, es una compilación sapiencial de origen judío con un claro propósito de summa de saber que da cuenta del único tratado sapiencial de la Ley oral, el Pirqué Abot, y del más relevante, también en el ámbito de la literatura sapiencial bíblica, que se recoge en la Ley escrita, los Proverbios de Salomón. De este modo, la tradición sapiencial de la Ley judía se completa con la sabiduría de la auctoritas clásica por excelencia, Aristóteles. Sin olvidar que en la Edad Media la filosofía, fundamentalmente la aristotélica, influyó mucho en el pensamiento de la comunidad judía en un intento de conciliar las revelaciones de la Ley con la razón ${ }^{18}$.

El propósito del compilador es crear un florilegio sentencioso que reúna las directrices fundamentales de la tradición sapiencial hebrea y que pueda ser asimilado por la ortodoxia cristiana; de ahí que suprima todas las referencias específicas a la Ley y a cualquier elemento, como nombres propios, que remita a un contexto judío; no obstante, la relevancia de las fuentes escogidas asegura su recepción por la comunidad sefardí y, por otro lado, la universalidad del contenido favorece su circulación y adaptación a la cultura medieval.

Buena prueba de ello la ofrece otra de las secciones del manuscrito que nos ocupa: los folios $72_{\mathrm{v}}\left(\operatorname{lxxiv}_{\mathrm{v}}\right)$ al $78_{\mathrm{v}}\left(\operatorname{lxxx}_{\mathrm{v}}\right)$ recogen los Dichos de sabios, aparte de sumas, es decir, sentencias de distintas auctoritates, entre ellos, Aristó-

17 La traducción hebrea ha sido editada por A. Loewenthal, Sefer Musre Haphilosophim (Sinnprüche der Philosophen), aus dem Arabischen des Honein Ibn Ishak in Hebräische übersetzt von Jebuda ben Salomo Alcharisi, Frankfurt, 1896; el «Capítulo de las Juntas de los Filósofos» se corresponde con los capítulos VIII, IX y X (págs. 61-68) de la versión hebrea, centrándose el capítulo $\mathrm{X}$ en los Dichos de Aristóteles. Véase también T. A. Perry, «Judeo-Christian Forces and Artistic Tension in Medieval Spanish Letters: The Case of the Libro de los buenos proverbios», La Chispa '87 Selected Proceedings of the Eighth Lousiana Conference on Hispanic Languages and Literatures, ed. Gilbert Paolini, New Orleans, Tulane University, 1987, págs. 251-256.

${ }^{18}$ En este sentido recomiendo la consulta, entre otros, de Yitzhar Baer, Historia de los judios en la España cristiana, Barcelona, Riopiedras Ediciones, 1981; Ahmed Chahlane, «Averroes, Maimonides, y la crisis en la comunidad judía medieval», Anales del Seminario de Historia de la Filosofía, 22, 2005, págs. 111-123; D. Gutas, Greek Thought Arabic Culture: the Graeco Arabic Translation. Movement in Baghdad and Early 'Abbasid Society (2nd-4th, 8th-10th Century), London, Routlegde, 1998; J. Martínez Gázquez, «La recepción de la cultura griega en el Occidente latino a través del mundo árabe», Antiquae Lectiones. La tradición clásica desde la Antigüedad al siglo XIX, ed. Juan Signes, Madrid, Cátedra, 2005; Moisés Orfali, Biblioteca de autores lógicos hispano judios (siglos XI-XV), Granada, Universidad de Granada, 1997; R. Ramón Guerrero, Filosofías árabes y judías, Madrid, Síntesis, 2001; D. Romano, La ciencia hispanojudía, Madrid, Editorial Mapfre, 1992; C. Sirat, Philosophie juive médiévale en pays de chrêtienté, Paris, Editions du Centre National de la Recherche Scientifique, 1983 y La Philosophie Juive au Moyen Âge, Paris, Editions du Centre National de la Recherche Scientifique, 1983; S. Vegas González, La Escuela de Traductores de Toledo en la historia del pensamiento, Toledo, Ayuntamiento de Toledo, 1998 
teles, Séneca, Cicerón, Ovidio, San Bernardo, Valerio Máxio y, a continuación, ff. $78_{\mathrm{v}}\left(\operatorname{lxxx}_{\mathrm{v}}\right)-84_{\mathrm{v}}\left(\mathrm{xxxvi}_{\mathrm{v}}\right)$, Palabras breves: dichos de sabios ${ }^{19}$. Por tanto, aunque las rúbricas que funcionan como títulos indiquen, en teoría, dos modos de compilación distintos, lo relevante es que dichos atribuidos a Séneca o Cicerón, o al propio San Bernardo, fueron de la mano con los de los «padres» ('abot') judíos.

Así las cosas, el proceso de compilatio llevado a cabo entre el Libro de los buenos proverbios, el Pirqué Abot y los Proverbios de Salomón da lugar a un nuevo producto literario, Palabras breves: dichos de sabios, que ejemplifica a la perfección el proceso y las técnicas de asimilación y transmisión del legado sapiencial judío a la Edad Media castellana.

Para finalizar este trabajo aporto la edición de Palabras breves: dichos de sabios, ff. $78_{\mathrm{v}}\left(\operatorname{lxxx}_{\mathrm{v}}\right)-84_{\mathrm{v}}\left(\mathrm{lxxxvi}_{\mathrm{v}}\right)$ del manuscrito 5644 de la Biblioteca Nacional de Madrid. Los criterios seguidos para la edición son los siguientes:

- Regularización de $u$ e $i$ con valor vocálico y $v, j$ e $y$ con valor consonántico.

- Simplificación de geminadas cuando carecen de valor fónico (por ejemplo $f f$ en $f$ ), así como la $l l$ final con valor lateral. Mantengo, no obstante, los grupos consonánticos cultos ( $p h$ o th)

- El signo tironiano se transcribe como $y$, excepto ante $i$ o hi que se utiliza $e$

- Utilización de $r$ en posición inicial y tras nasal.

- Utilización de $m$ ante $b$ y $p$.

- Los numerales se transcriben en cifras romanas o arábigas según estén en el manuscrito, siempre con mayúsculas; utilizaré IV en lugar de IIII y IX por VIIII.

- Se desarrollan las abreviaturas y sobrescritos.

- Regularización del uso de mayúsculas y minúsculas, así como la separación de palabras. Las contracciones de palabras se resuelven mediante apóstrofo y se mantienen las palabras formadas con vocales protéticas.

- Acentuación de acuerdo con la normativa, también para palabras homonímicas.

- La puntuación se acomodará a las normas actuales para facilitar la lectura y comprensión.

- Los corchetes cuadrados indican las adiciones del editor y los triangulares las supresiones. Dado que mi propósito fundamental es dar a conocer Palabras breves: dichos de sabios (Biblioteca Nacional de Madrid

\footnotetext{
${ }^{19}$ La edición y estudio de los Dichos de sabios, aparte de sumas lo llevo a cabo en otro trabajo que será publicado en breve.
} 
5644), únicamente corrijo o mejoro el texto, de acuerdo con los otros testimonios, en aquellos casos que resulte necesario para la compresión de la obra.

- Se acompaña la edición con un aparato de variantes que tiene en cuenta todos los testimonios castellanos del Libro de los buenos proverbios que comparten toda la materia o algún pasaje con nuestra colección de sentencias ${ }^{20}$. Las siglas empleadas se corresponden con los siguientes manuscritos:

- (L) Madrid, Biblioteca del Monasterio de El Escorial, L-III-2 (ff. 26$67_{\mathrm{v}}$ ), concretamente ff. $55_{\mathrm{vb}}-57_{\mathrm{ra}}$.

- (h) Madrid, Biblioteca del Monasterio de El Escorial, h-III-1 (ff. 96$\left.130_{\mathrm{r}}\left[41_{\mathrm{r}}-57_{\mathrm{v}}\right]\right)$, en nuestro caso ff. $46 \mathrm{r}-47 \mathrm{v}$.

- (S) Salamanca, Biblioteca Universitaria, 1763 (ff. 87 $-111_{\mathrm{v}}$ ), el material común ff. $91_{\mathrm{va}}-92_{\mathrm{rb}}$.

- (G) Madrid, Biblioteca Nacional, 17814 (ff. 125 $-131_{\mathrm{v}}$ [132 $]$, concretamente ff. $126_{\mathrm{ra}}-126_{\mathrm{rb}}$.

- (B) Madrid, Biblioteca Nacional, 9428 (ff.18 ${ }_{\mathrm{r}}-20_{\mathrm{v}}$ ), comparte con nuestra colección de sentencias ff. $18_{\mathrm{r}}-19$.

- (P) Madrid, Biblioteca del Monasterio de El Escorial, S.II.13 (ff. 19-25 ), concretamente ff. $20_{\mathrm{v}}-21_{\mathrm{v}}$.

- (F) Madrid, Biblioteca Nacional, 4515 (ff.1-142), Floresta de filósofos, las sentencias proceden de ff. $34_{\mathrm{rb}}-35_{\mathrm{ra}}$.

- (Sa) También se ha tenido en cuenta el Llibre de savieva por lo que respecta únicamente al contenido, siguiendo el manuscrito 921 de la Biblioteca Nacional de Madrid (ff. $31_{\mathrm{va}}-43_{\mathrm{vb}}$, especialmente, ff. $34_{\mathrm{rb}}-35_{\mathrm{ra}}$ ).

Para aquellas sentencias que provienen del Pirqué Abot y de los Proverbios de Salomón, sólo se indica la referencia de procedencia, el capítulo y la sección $^{21}$.

${ }^{20}$ El manuscrito V-6-75 de la Real Academia Española (Madrid), ff. $45_{\mathrm{r}}-48_{\mathrm{v}}$, es el único de los testimonios del Libro de los buenos proverbios que no ha conservado el «Capítulo de las juntas de los filósofos» de donde proceden las sentencias de Palabras breves: dichos de sabios. Es innegable que el Libro de los buenos proverbios necesita una edición crítica que aclare la tradición textual de la obra, teniendo en cuenta todos los testimonios castellanos conservados, así como la versión árabe y hebrea. Tengo noticia de que recientemente, aunque no he podido consultar, ha visto la luz la edición de Christy Bandak, Libro de los buenos proverbios. Estudio y edición crítica de las versiones castellana y árabe, Zaragoza, Instituto de Estudios Islámicos y del Oriente Próximo, 2007.

${ }^{21}$ Las referencias al tratado Pirqué Abot se corresponden con la edición de Carlos del Valle, La Misná, Madrid, Editora Nacional, 1981, págs. 786-810. 
[78 $\left(\right.$ LXXX $\left.\left._{\mathrm{v}}\right)\right] \quad$ PALABRAS BREVES: DICHOS DE SABIOS

(1) El franco ${ }^{22}$ siempre $^{23}$ es honrado ${ }^{24}$ maguer ${ }^{25}$ sea pobre

(2) La cobdiçia es probre present' 26

(3) El que no es cobdicioso ese á la ${ }^{27}$ riqueza que ${ }^{28}$ paresçe ${ }^{29}$

(4) En dezir omne no sé ${ }^{30}$ es medio saber ${ }^{31}$

(5) $\mathrm{En}^{32}$ responder ${ }^{33}$ aína da cabsa al ${ }^{34}$ omne d'errar ${ }^{35}$

(6) En pensar omne ${ }^{36}$ en las cosas muéstrase ${ }^{37}$ segund ${ }^{38}$ deve ser ${ }^{39}$

(7) El grand uso aguza ${ }^{40}$ el entendimiento ${ }^{41}$

(8) El buen ${ }^{42}$ enseñamiento ${ }^{43}$ escusa $^{44}$ el linaje $^{45}$

(9) El themor ${ }^{46}$ de $^{47}$ Dios es el ${ }^{48}$ vestido ${ }^{49}$ de los sabios ${ }^{50}$

(10) La iproquesía es vestido ${ }^{51}$ de los torpes ${ }^{52}$

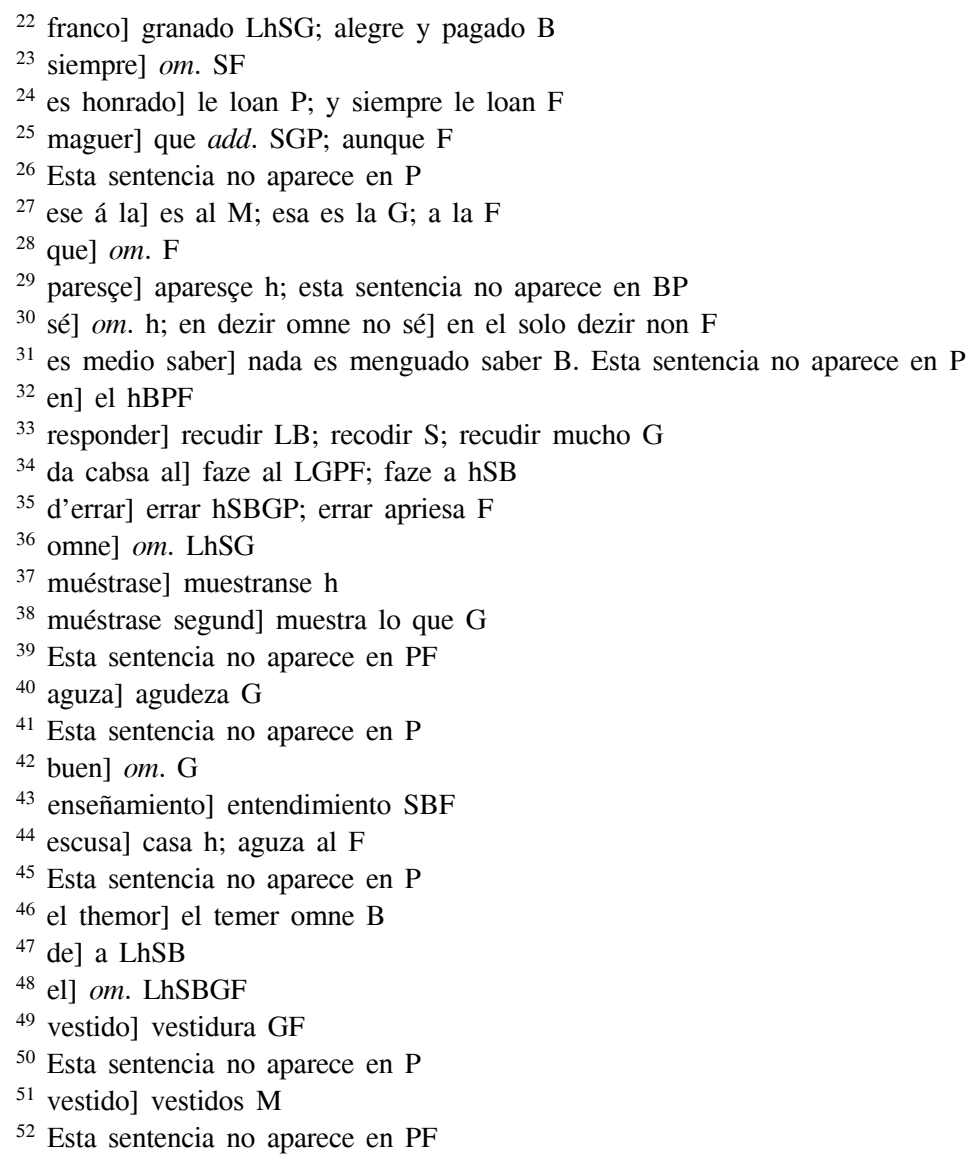


(11) Aver ${ }^{53}$ vida con el loco ${ }^{54}$ es pena del coraçón ${ }^{55}$

(12) Quien mucho se trabaja con las ${ }^{56}$ mugeres par ${ }^{57}$ es del loco ${ }^{58}$

(13) $\left[79_{\mathrm{r}}\left(\right.\right.$ LXXXI $\left.\left._{\mathrm{r}}\right)\right]$ En afregirse ${ }^{59}$ omne por ${ }^{60}$ lo pasado es perdiçión ${ }^{61} \mathrm{del}^{62}$ tiempo ${ }^{63}$

(14) El que se mete ${ }^{64}$ en $\operatorname{los}^{65}$ grandes peligros, aventura su alma

(15) Por $^{66}$ desear el ${ }^{67}$ omne mucho multiplica mansilla ${ }^{68}$

(16) El sofrir esfuerça ${ }^{69}$ el ardimiento que omne ${ }^{70}$ quiere ${ }^{71}$ y es fruto de consolaçión ${ }^{72}$

(17) El amigo del torpe bive ${ }^{73}$ engañado

(18) El que se mete ${ }^{74}$ en ${ }^{75}$ aventuras ${ }^{76}$ a las vezes desfallesçe ${ }^{77}$

(19) El que se conosçe non se pierde ant' ${ }^{78}$ los omnes

(20) El que ${ }^{79}$ es más su saber que su seso es dañamiento d'él ${ }^{80}$

${ }^{53}$ aver] el aver B; fazer $\mathrm{F}$

${ }^{54}$ loco] sandio LhSBGP

${ }^{55}$ es pena del coraçón] espensa es del coraçon B; es vida de coraçon P; es pena del coraçon del cuerdo $\mathrm{F}$

${ }^{56}$ con las] en LhBF; de SG; por P

${ }^{57}$ par] a par h; egual es al P; om. F

58 loco] y sera pobre add. F

59 afregirse] trabajarse LhSBGP

${ }^{60}$ por] de LhSBGF

${ }^{61}$ perdiçión] predicaçion $\mathrm{h}$

62 es perdiçión del] pierde el $\mathrm{G}$

${ }^{63}$ Esta sentencia no aparece en $\mathrm{F}$

${ }^{64}$ mete] aventura $\mathrm{S}$

$\left.{ }^{65} \mathrm{los}\right] \mathrm{om}$. B

${ }^{66}$ por] de P. Hasta aquí el folio126vb del manuscrito G; más de la mitad de la segunda columna en blanco. El folio siguiente (127) también en blanco.

$\left.{ }^{67} \mathrm{el}\right]$ om. hBPF

68 multiplica mansilla] vienen al omne muchas mansiellas $\mathrm{L}$; viene al omne muchas mansiellas hS; viene grandes manzillas $\mathrm{B}$; vienen las grandes manzillas $\mathrm{P}$; le vienen muchas manzillas $\mathrm{F}$

${ }^{69}$ esfuerça] es fuerza del $\mathrm{hF}$

${ }^{70}$ que omne] en lo que el hombre $\mathrm{F}$

${ }^{71}$ quiere] fazer add. LhSPF

72 esfuerça (...) consolaçión] es fuerça y ardimiento de lo que omne quiere otrosi es esfuerço de coraçon $\mathrm{B}$

${ }^{73}$ bive] es LhSBPF

${ }^{74}$ mete] miente $\mathrm{P}$

75 en] a Lh

${ }^{76}$ aventuras] aventura $\mathrm{P}$; los grandes peligros $\mathrm{F}$

77 a las vezes desfallesçe] desfallesçe a las vezes S. Esta sentencia no aparece en la versión hebrea.

78 ant'] entre B

${ }^{79}$ el que] de quien $\mathrm{F}$

${ }^{80}$ es dañamiento d'él] su saber le daña F. Esta sentencia no aparece en B 
(21) El provador ${ }^{81}$ es más sabidor ${ }^{82}$ que el físico ${ }^{83}$

(22) Quando ${ }^{84}$ fueres ensañado ${ }^{85}$, cállate

(23) Quien su saber provó, no le fará mal la torpedad ${ }^{86}$

(24) Quien se esfuerça ${ }^{87}$, no se arrepiente ${ }^{88}$

(25) Quien se aventuró, vídose en grand afrenta ${ }^{89}$

(26) Quien se apresura más que no debe, engáñase ${ }^{90}$

(27) El que pensó, estorçió ${ }^{91}$

(28) El que preguntó, aprendió ${ }^{92}$

(29) El que quiso levar ${ }^{93}$ lo que non pudo ${ }^{94}$, embargose ${ }^{95}$

(30) Las pruevas ${ }^{96}$ no han fin ${ }^{97}$

(31) El sesudo siempre añade ${ }^{98}$ en las ${ }^{99}$ pruevas ${ }^{100}$

(32) El uso es rey sobre todas las cosas ${ }^{101}$

(33) Non se pueden cambiar las cosas naturales 102

${ }^{81}$ provador] provar $\mathrm{h}$; esperimentador $\mathrm{F}$

${ }^{82}$ sabidor] sabio SPF

${ }^{83}$ Esta sentencia no aparece en B

${ }^{84}$ quando] non add. hPF

85 ensañado] sañudo L; enseñado hSBPF

${ }^{86}$ quien (...) torpedad] el que non prueva su saber no puede ser seguro que non le faga mala torpedat LB; el que no prueva su saber no puede ser seguro que non le faga mal la torpedat h; el que no tiene pro su saber non puede ser seguro que non le faga mal su torpedat $\mathrm{S}$; el que non tiene su saber non puede saber nin ser seguro que non le faga mal su torpedat $\mathrm{P}$. Esta sentencia no aparece en F; tampoco se halla en la versión hebrea.

87 esfuerça] esforço SPF

${ }^{88}$ arrepiente] arrepentio SPF

${ }^{89}$ quien (...) afrenta] quien se aventura viose en grande afruenta h; quien se aventura si escapa non se arrepiente pero veese en gran afruenta B

90 más que no deve engáñase] mas que deve engañose $\mathrm{F}$

91 estorçió] estudio PF

92 aprendió] apriso LhSB

93 quiso levar] quiso llegar a S; quiere llevar B

${ }^{94}$ pudo] puede $\mathrm{B}$

95 embargose] engañose $\mathrm{S}$; en pruevas non ha fin B; enbargase P. Esta sentencia no aparece en $\mathrm{F}$

96 pruevas] penas $\mathrm{PF}$

97 Esta sentencia, en B, ha sido fusionada a la anterior

98 añade] acreçienta $\mathrm{F}$

99 las] sus Lh; om. P

100 Esta sentencia no aparece en B

101 cosas] del mundo add. B

102 non (...) naturales] todas las cosas del mundo se pueden cambiar sino las naturas L; todas las cosas del mundo non se pueden cambiar sino las naturas $\mathrm{h}$; todas las cosas del mundo se pueden amar sinon las naturas $\mathrm{S}$; todas las cosas del mundo se pueden acabar sinon las naturas; el mundo se canbia y non la natura P. Esta sentencia no aparece en F 
(34) En todas las cosas ${ }^{103}$ puede aver ${ }^{104}$ arte salvo ${ }^{105}$ en el juizio ${ }^{106}$

(35) Al sabio todos le acatan ${ }^{107}$

(36) Con el seso y sosegamiento ${ }^{108}$ cumple omne ${ }^{109}$ maguer $^{110}$ [non s.l] sea ${ }^{111}$ razonado ${ }^{112}$

(37) $\mathrm{El}^{113}$ abreviamiento ${ }^{114}$ segura al $^{115}$ dezidor del mal entendimiento del $^{116}$ oidor $^{117}$

(38) $\left[79_{\mathrm{v}}\left(\mathrm{LXXXI}_{\mathrm{v}}\right)\right]$ Fallada $^{118}$ la fin de la verdad ${ }^{119}$ escusan $^{120}$ mucho preguntar $^{121}$, y quien ${ }^{122}$ no falló la fin ${ }^{123}$ de la verdad estuvo ${ }^{124}$ afondado ${ }^{125}$ en la torpedad, y arredrado con el sabor ${ }^{126}$ de la puerta del embargamiento $^{127}$, y tollido con el mal uso de presçiar el aprender ${ }^{128}$

\footnotetext{
103 cosas] del mundo add. BP
}

104 aver] omne fazer LhSB

${ }^{105}$ salvo] sinon LhSB

${ }^{106}$ Esta sentencia no aparece en PF

107 al sabio (...) acatan] el que saben que es sabio los ojos todos le catan L; el que saben que es sabio todos le catan a los ojos $\mathrm{S}$; el que saben que es sabio todos los ojos le catan B; el que las gentes saben que es sabio a los ojos todos le miran F. Esta sentencia no aparece en $\mathrm{P}$

${ }_{108}$ sosegamiento] con el sosegamiento L; con el asosegamiento hSB; con el sosiego F

109 omne] el hombre $\mathrm{F}$

110 maguer] que $a d d$. $\mathrm{S}$; aunque $\mathrm{F}$

111 sea] bien $a d d$. hF. Esta sentencia no aparece en $\mathrm{P}$

${ }^{112}$ En la versión hebrea no aparece esta sentencia, en su lugar se recoge la que sigue, que no aparece en la traducción castellana: «Die Rede wird geschädigt durch Abschweifungen und Kürze» (p. 68) [Un discurso pierde su valor por la falta de orden y por la brevedad]

113 el] con el LhSPF

114 abreviamiento] avisamiento $\mathrm{P}$; abreviar se $\mathrm{F}$

115 segura al] segurase el Lh; segurase $\mathrm{S}$; asegura $\mathrm{F}$

116 del] mal add. h; dolorido add. $\mathrm{S}$

117 al dezidor (...) oidor] el alma dezidor de mal pensamiento P; el dezir del mal entendimiento F. Esta sentencia no aparece en B

118 fallada] quien fallo LhSB

119 verdad] coita B

120 escusan] escusol LhSB

121 mucho preguntar] de muchas vergüenzas LhB; de mucho preguntar B. Esta sentencia concluye aquí en B

122 quien] el que LhS

${ }^{123}$ la fin] el fino $\mathrm{S}$

124 estuvo] estudose $\mathrm{S}$

125 afondado] afontado L; afrontado h; safondando $\mathrm{S}$

126 sabor] saber h

127 embargamiento] averiguamiento Lh; abrigamiento $\mathrm{S}$

128 aprender] aprendedor $\mathrm{h}$ fallada la fin (...) aprender] quien fallo el fundamento de la verdad escusole de muchas preguntas el que non fallo el fundamiento de la verdad estuvo afogado en la torpedad con el mal uso despreçian el aprender P; quien falla el fin de la verdad escusado es de mucho preguntar el que no fallo el fin de la verdad estuvo çabullido en el rio de la torpeza $\mathrm{F}$ 
(39) Quien se cuita ${ }^{129}$ por las cuitas ${ }^{130}$ de su amigo ${ }^{131}$ es más loado que ${ }^{132}$ darse a ${ }^{133}$ espaçio ${ }^{134}$

(40) En sofrir omne sus cuitas ${ }^{135}$ es más loado ${ }^{136}$ que quien ${ }^{137}$ se quexase

(41) Non ha cosa por que ${ }^{138}$ tanto se ${ }^{139}$ pierda $^{140}$ el bien y la merçed como por durar el ${ }^{141}$ mal fazer ${ }^{142}$

(42) Quien quiere ${ }^{143}$ servir ${ }^{144}$ al rey ${ }^{145} \sin$ buen ${ }^{146}$ enseñamiento sale ${ }^{147}$ de la salud a la muerte ${ }^{148}$

(43) El sofrir al ${ }^{149}$ señorío es grave $y^{150}$ desçender a la aviltança ${ }^{151}$ es rafez $^{152}$

(44) Con el pensamiento agudo se ${ }^{153}$ alcança ${ }^{154}$ consejo a las cosas ${ }^{155}$ graves ${ }^{156}$

${ }^{129}$ quien se cuita] en se cuitar omne LSP; en se ayuntar onbre h; en coitarse omne B

${ }^{130}$ las cuitas] la coita B

131 su amigo] sus amigos hP

132 que] en add. B

133 a] om. hSB

${ }^{134}$ que darse a espaçio] que cuitarse honbre por las suyas P. Esta sentencia no aparece en F

135 en sofrir omne sus cuitas] en seer omne sofrido en las cuitas que a LhS; en seer omne sofrido en las cuitas B; en dar espaçio por las cuitas P; en ser hombre sufridor en sus mesmas cuitas F

136 loado] y mas sesudo add. B

137 quien] si LhSBPF

138 que] donde $\mathrm{h}$

139 se] om. LSB

140 pierda] pierde $\mathrm{h}$; omne add. $\mathrm{B}$

141 por durar el] ser durable en Lh; por ser durable en B; por ser omne durable S; ser honbre durable $\mathrm{P}$

142 Esta sentencia no aparece en $\mathrm{F}$

143 quiere] se da a $\mathrm{F}$

144 servir] seguir SPF

145 al rey] a los reyes $\mathrm{F}$

146 buen] om. $\mathrm{P}$

147 sale] fable $\mathrm{S}$

148 sale (...) muerte] corta su vida P. Esta sentencia no aparece en B

149 el sofrir al] en sobir omne al Lh; en sobir a B; subir a P; el subir al F

$150 \mathrm{y}$ ] en $a d d$. L; el $a d d$. hSBPF

151 aviltança] vilteza $\mathrm{L}$; om. $\mathrm{P}$; abiltaçion $\mathrm{F}$

152 rafez] rehez $\mathrm{B}$; raez $\mathrm{PF}$

153 se] om. LhSBG

154 alcança] alça B; omne add. LhBG; omne buen add. $\mathrm{S}$

155 cosas] coitas $\mathrm{B}$

156 con el pensamiento (...) graves] por conclusion de los sesos y con el pensamiento agudo alcança hombre el buen consejo en las cosas graves $\mathrm{F}$. Esta sentencia no aparece en $\mathrm{P}$ 
(45) Mansamente ${ }^{157}$ puede omne ${ }^{158}$ aver $^{159}$ las cosas mejor que las ${ }^{160}$ demanda 161

(46) Con ${ }^{162}$ la palabra blanda dura el amor en los coraçones ${ }^{163}$

(47) En la ${ }^{164}$ omildad se acaban todas las cosas

(48) En ${ }^{165}$ el espaçio ${ }^{166}$ de la ${ }^{167}$ voluntad es la ${ }^{168}$ vida sabrosa y ${ }^{169}$ cúmplese el ${ }^{170}$ alegría

(49) Con el fablar y el callar en su lugar es la reverençia ${ }^{171}$

(50) Con la razón creçe el onor y ensálçase la nobleza ${ }^{172}$

(51) Con la mesura es la ${ }^{173}$ amistad

(52) Con ${ }^{174}$ omildad cresçe el amor ${ }^{175}$

(53) Con la castidad ${ }^{176}$ son ${ }^{177} \operatorname{los}^{178}$ buenos fechos ${ }^{179}$

(54) Con el ${ }^{180}$ bien fazer es el ${ }^{181}$ señorío

(55) $\left[80_{\mathrm{r}}\left(\right.\right.$ LXXXII $\left.\left._{\mathrm{r}}\right)\right]$ Con el sofrir y la justiçia ${ }^{182}$ vençe omne sus enemigos ${ }^{183}$

157 mansamente] con mansedumbre B

158 omne] mejor add. LhB; el hombre F

159 aver] mejor add. SF

160 cosas mejor que las] cosas que LhSBF; lo que G

161 Esta sentencia no aparece en $\mathrm{P}$

162 con] en $\mathrm{S}$; ca con $\mathrm{B}$

163 coraçones] de los omnes add $\mathrm{F}$

164 en la] con BF

165 en] om. $\mathrm{P}$

166 espaçio] espanto $\mathrm{h}$

167 la] om. G

168 es la] faze omne LhSBGPF

169 e] otrosi B

170 cumplese el] cumplese la $\mathrm{P}$; cumple su $\mathrm{F}$

171 con el fablar (...) reverençia] con el buen callar es la buena reverençia L; con el buen callar es la reverençia bSG; con fablar el omne en su lugar B; en el buen callar es la reverençia PF

172 con la razón (...) nobleza] con el fablar en su logar y con razon creçe el prez y enxalçase la nobleza L; con el fablar en su logar creçe el prez y enxalçase la nobleza hS; con razon y creçe el prez y la ensalça B; con el fablar en su lugar cresçe el preçio y se ençalsa la nobleza G; fablar en su lugar y consejo ensalça y ennoblesçe P; con el fablar en su lugar y con razones cresçe el balor y ensalçase la nobleza $\mathrm{F}$

173 es la] viene el LG; viene la hSBPF

174 con] en la h; con la LBP

175 Esta sentencia no aparece en $\mathrm{F}$

176 castidad] caridad h

177 son] cresçen B

178 los] omnes add. S

179 Esta sentencia no aparece en $\mathrm{P}$

180 el] om. S

181 es el] om. $\mathrm{P}$

182 con el sofrir y la justiçia] con justiçia LhB; con la justiçia SGPF

183 vençe omne sus enemigos] vençe omne los enemigos L; vençen los omnes los enemigos $\mathrm{S}$; vençe omne enemigos $\mathrm{G}$; vençe el honbre sus enemigos $\mathrm{P}$; vençen los hombres sus enemi- 
(56) Con la mansedumbre se sirve ${ }^{184}$ onme $^{185}$ de los coraçones ${ }^{186}$

(57) Por el honramiento se gana ${ }^{187}$ nombradía de bondad ${ }^{188}$

(58) Quien faze bien y merçed gana suma granada 189

(59) Con $^{190}$ la lealtad dura la hermandat ${ }^{191}$

(60) Con ${ }^{192}$ la verdad cresçe la bondad ${ }^{193}$

(61) Quien bien mira ${ }^{194}$ las cosas alegará ${ }^{195}$ buenos enxemplos

(62) Lo que non faze la razón faze el tiempo, y lo que non faze el tiempo faze la razón 196

(63) Quien bien ${ }^{197}$ sabe las cosas puja ${ }^{198}$ en su bondad ${ }^{199}$

(64) El sabor del comer y del bever es en la salud ${ }^{200}$

gos F. A continuación aparece la siguiente sentencia que no ha sido recogida en nuestro testimonio, ni tampoco en B: Con el sofrir creçen los ayudadores L; con sofrir creçen los ayudadores h; con el sofrir vençen los ayudadores $\mathrm{S}$; con el sofrir cresçen los cuidadores $\mathrm{G}$

184 se sirve] sirvese LS; sirve h; sirven P

185 onme] los honbres PF

186 coraçones] de los otros add. B; ajenos add. F

187 por el honramiento se gana] con ondramiento gana omne LhS; con fazer omne onra a todos gana $\mathrm{B}$; con ornamiento gana omne $\mathrm{G}$; en honrar a otra ganaras $\mathrm{P}$; con los honramientos gana el hombre $\mathrm{F}$

188 nombradía de bondad] bondad de nombradia G; nonbradia y bondad P

189 quien faze (...) granada] por fazer omne algo y merçet mereçe suma granada L; por fazer omne algo y merçet gana fama granada h; por fazer omne merçet y dar algo meresçe suma granada $\mathrm{S}$; y por fazer alguna merçed metese en fama granada $\mathrm{P}$; por fazer hombre algo no meresçe suma granada F. Ni en B ni en G aparece esta sentencia.

190 con] en LhSF

191 En G no aparece esta sentencia

192 con] en LhSF

193 bondad] el amor F con la (...) bondad] a la verdad responde verdad a la mentira otro que tal P. En G no aparece esta sentencia

194 quien bien mira] parando mientes en LF; parando omne mientes en hSBG

195 alegará] puede omne retraer Lh; puede omne aver S; puede departir omne B; puede retener $\mathrm{G}$; puede hombre recoger $\mathrm{F}$. Esta sentencia no aparece en $\mathrm{P}$

196 Esta sentencia no aparece en ningún testimonio, en su lugar: Los dias fazen al omne maestro de las cosas LhSPF; los dias fazen a los omnes maestros de las cosas B; en G está unida a la anterior: parando omne mientes en las cosas puede retener buenos enxenplos ca los dias fazen al onbre maestro de las cosas

${ }^{197}$ bien] om. SGP. Tampoco se halla en la versión hebrea, en su lugar: «Die Tage lehren dich Weisheit» (p. 66) [Los días te enseñan la sabiduría]

198 las cosas puja] la mingua deste sieglo es eñadiençia LhS; la mengua deste mundo qual es eñade su bondat B; las menguas deste siglo es añadimiento $\mathrm{G}$; la mengua deste siglo añade $\mathrm{P}$

199 Esta sentencia no aparece en F. En la versión hebrea, a continuación, se incluye la siguiente sentencia que no aparece en la versión castellana: «Die Stunden bringen es mit sich, dass sich die Unglücksfälle mit einander verbinden» (p. 66) [Las horas traen consigo que a las desgracias se les unan más desgracias].

200 el sabor (...) salud] con la salut es el sabor del comer y del bever LhS; con la salud viene el sabor del comer y bever B; quien es salud es el sabor del comer y del bever G; con la salud es la bondad comer y bever regladamente P; con la salud es el sabor de comer y de beber F 
(65) Con las cuitas ${ }^{201}$ es la mala vida y túrbanse ${ }^{202}$ los otros bienes ${ }^{203}$

(66) Por negar ${ }^{204}$ el bien ${ }^{205}$ y la merçed ${ }^{206}$ se pierde ${ }^{207}$ el bien fazer ${ }^{208}$

(67) Quien se aína enoja su amistad poco tura ${ }^{209}$

(68) El omne sañudo ${ }^{210}$ peligro es de su compañía ${ }^{211}$

(69) El escaso siempre es abiltado maguer sea ${ }^{212}$ rico $^{213}$

(70) Vil compañía se llaman los bienes temporales ${ }^{214}$

(71) La madre de todos es la tierra ${ }^{215}$

(72) El omne próspero dizen venturoso mas non bienaventurado ${ }^{216}$

201 con las cuitas] con la cuita S; con la coita B

202 túrbanse] tornase $\mathrm{Lh}$; tornan $\mathrm{S}$; tornanse $\mathrm{G}$

203 con las cuitas (...) otros bienes] en la cuita es la mala vida P. Esta sentencia no aparece en F. En la versión hebrea, a continuación, se recoge la siguiente sentencia que no aparece en la traducción castellana: «Wer sich mit seiner Wohlthätigkeit brüstet, verdient, dass das Glück ihm den Rücken kehrt» [El que se vanagloria de sus bondades (u obras de caridad), la buena suerte le da la espalda]

204 negar] omne add. hSB

205 el bien y la] om. S

206 merçed] amistad G

207 se pierde] conviene que pierda omne LhBG; conviene que pierda $\mathrm{S}$

208 fazer] om. B. Esta sentencia no aparece en PF

${ }^{209}$ quien se (...) tura] el amiztat del que se enoja aina se tuelle L; el amiztat del que aina se enoja aina se tuelle h; la amiztat del que aina se enoja aina se tuelle $S$; el amiztat del que aina se ensaña aina se tuelle B; el amistad del que aina se enoja aina se quita G; amistad del que aina se enoja aina se quita F. Esta sentencia no aparece en $\mathrm{P}$

210 sañudo] es add. LhSBG; sañoso $\mathrm{P}$

211 es de su compañía] para su compañero LhSBP; de su compañero G. Esta sentencia no aparece en F. En la versión hebrea, a continuación, se recoge la siguiente sentencia, probablemente procedente del Talmud, que no aparece en la traducción castellana: «Wer schnell vorwärts schreitet, schädigt seinen Blick» (p.66) [A quien camina con prisa, se le nubla la vista].

212 maguer sea] maguer siempre sea L; maguer sea siempre h; maguer que sea SPF; maguer que siempre sea $\mathrm{G}$

213 Termina aquí la sección perteneciente al Libro de los buenos proverbios

${ }^{214}$ Esta sentencia, al igual que las tres siguientes, no forma parte ni del Libro de los buenos proverbios, ni del Pirkei Avot, ni de los Proverbios de Salomón. Su sentido es tan general que dificulta su localización. De todos modos, sintetiza un principio que se repite en todas las colecciones de sentencias, por ejemplo, en el Libro de los cien capítulos (edición de Marta Haro Cortés, Libro de los cien capítulos (Dichos de sabios en palabras breves e complidas), Madrid, Frankfurt am Main, Vervuert-Iberoamericana, 1998), encontramos: «La riqueza es mal bienquisto», pág. 155 .

${ }^{215}$ En el Génesis, 2, 7 se dice: «Entonces Yavé Dios formó al hombre del polvo de la tierra, le insufló en sus narices un hálito de vida y así llegó a ser hombre un ser viviente»; en el Lucidario se explica: «La primera [generación] fizo a Adam que non ouo padre nin madre, que en lugar de padre ouo a Dios quel formo e crio; e por madre ouo la tierra de que fue fecho [...]», Los Lucidarios Españoles, ed. Richard P. Kinkade, Madrid, Gredos, 1968, cita, pág. 120.

${ }^{216}$ La parte final de la sentencia número 98 presenta cierta simetría en el sentido: «El que compra buena fama, compra para sí; el que se trabaja por la fe compra vida perdurable». 
(73) El favor dado a la lengua es quando calla ${ }^{217}$

(74) La virtud faz' perfecto al que la tiene y dale buen galardón ${ }^{218}$

(75) Sea tu casa aparejada por los sabios y embuélvete en el polvo de sus pies y beve en el tiempo de tu sed sus palabras ${ }^{219}$

(76) $\left[80_{v}\left(\right.\right.$ LXXXII $\left.\left._{v}\right)\right]$ Sea tu casa abierta largamente y serán los pobres los fijos de tu casa y no multipliques fabla con muger; con su muger dixeron ¡quánto más con muger ajena!, y de aquí dixeron los sabios que todo aquel que amochigua fabla con muger acarrea daño a sí mismo y desirve a Dios, y su fin será en pecado mortal ${ }^{220}$

(77) Faz para ti maestro y compra para ti amigo y judga a todo omne a buena parte 221

(78) Aléxate de mal vezino y non te acompañes con el malo y non te desfiuzes de la pena present' ${ }^{222}$

(79) Non te fagas así como los que son delant' los alcaldes, y más quando estovieren los del pleito ante ti, antes serán ante ti maliciosos, y quando se partieren de ti, tenlos por justos por quanto resçibieron sobre sí el yugo 223

(80) Mucho serás escuadriñador a los testigos y aperçíbete en tu fabla por que d'ella no se abesen a mentir ${ }^{224}$

(81) Ama el ofiçio y aborresçe la grandía y non te fagas conosçer al cabdillo 225

(82) Aperçibidvos en vuestras palabras que no vos condenedes por ellas ${ }^{226}$

(83) Siempre sed de aquellos que aman la paz y andan en ella 227

(84) El que no aprende, muerte meresçe y el sabio por corona será 228

(85) Si yo no só para mí, quién será para mí. Y si yo no só quién, y si agora no lo só, quándo lo seré 229

217 Esta sentencia es tan general que se multiplican los paralelismos, sin ir más lejos en el Libro de los buenos proverbios, leemos: «Mejor es callar que non dezir omne palabra errada», pág. 68, o «La mejor sapiençia de los buenos es el callar», pág. 69.

218 Esta máxima podría considerarse como la propia definición de la obras sapienciales, las similitudes con otras obras de sentencias serían innumerables.

219 Pirqué Abot 1, 4

220 Pirqué Abot 1, 5

221 Pirqué Abot 1, 6

222 Pirqué Abot 1, 7

223 Pirqué Abot 1, 8

224 Pirqué Abot 1, 9

225 Pirqué Abot 1, 10

226 Pirqué Abot 1, 11

227 Pirqué Abot 1, 12

228 Pirqué Abot 1, 13

229 Pirqué Abot 1, 14 
(86) Di poco y faz mucho y resçibe a todo omne con abtoridad de buena parte $^{230}$

(87) $\left[81_{\mathrm{r}}\left(\right.\right.$ LXXXIII $\left.\left._{\mathrm{r}}\right)\right]$ Faz para ti maestro y apártate de las debdas ${ }^{231}$

(88) Todos mis días creçí entre los sabios y no fallé para el cuerpo mejor qu'el callar, y el fazer es la raíz que no la pedricaçión, y todo aquel que amochigua palabras amochigua pecado ${ }^{232}$

(89) El mundo es fundado sobre tres cosas: sobre la justiçia y sobre la verdad y sobre la paz ${ }^{233}$

(90) ¿Quál es la vía derecha que omne deve aver para sí? Aquélla que es corona para el que la faze y con la qual lo coronan los omnes ${ }^{234}$

(91) Sey aperçebido en el mandamiento ligero así como en el mandamiento grave, que non sabes el galardón de los mandamientos ${ }^{235}$

(92) Sey así pensoso en fazer el mandamiento con respecto de su galardón, y el pecado con galardón de su desfaçimiento ${ }^{236}$

(93) Para mientes en tres cosas y no vernás a pecar: sepas que está ensomo de ti ojo que vee y oreja que oye y que todos tus fechos que son en libro escriptos ${ }^{237}$

(94) Fermoso es dezir sabio en la ley y en las vías mundanales porque el trabajo de amas las cosas fazen olvidar el pecar ${ }^{238}$

(95) Sed aperçebidos con los grandes señores que no açercan a sí los peones sino por lo que ellos han menester, y amuéstranse amadores en el campo en el tiempo de su provecho y no se paran con el omne de su angustia ${ }^{239}$

(96) $\left[81_{v}\left(\right.\right.$ LXXXIII $\left.\left._{v}\right)\right]$ No te apartes de la compañía y te fíes en ti fasta el día de tu muerte, y no judgues a tu próximo fasta que llegues al estado en que está, y no digas palabras que sean imposibles de oír pues que su fin es que pueda ser oída ${ }^{240}$

(97) El nesçio no theme de pecar, y el mundanal no será justo, y el vergonçoso no aprenderá, y el airado no enseñará, y todos aquellos que amochiguan mercaduría no pueden ser sabios; y el lugar do omnes no son, aperçíbite tú de ser omne ${ }^{241}$

\footnotetext{
230 Pirqué Abot 1, 15

231 Pirqué Abot 1, 16

232 Pirqué Abot 1, 17

233 Pirqué Abot 1, 18

234 Pirqué Abot 2, 1

235 Pirqué Abot 2, 1

236 Pirqué Abot 2, 1

237 Pirqué Abot 2, 1

238 Pirqué Abot 2, 2

239 Pirqué Abot 2, 3

240 Pirqué Abot 2, 4

241 Pirqué Abot 2, 5
} 
(98) El que amochigua carne amochigua gusanos, y el que amochigua gusanos, amochigua cuidados; el que amochigua mugeres amochigua forniçio y fechizos; el que amochigua siervos amochigua robos, el que amochigua siervas amochigua forniçio; el que amochigua saber amochigua vida; el que amochigua estud[i]o, amochigua sabiduría; el que amochigua consejo amochigua entendimiento, y el que amochigua limosna amochigua paz; el que compra buena fama, compra para sí; el que se trabaja por la fe compra vida perdurable ${ }^{242}$

(99) Si fueres bueno y guardares la fee no digas que as fecho mucho, porque para esto eres criado ${ }^{243}$

(100) Si quisieres saber quál es la vía derecha en que se deve el omne llegar, dixo un sabio que buen ojo, otro dize buen amigo, otro dize que buen vezino. [82 $\left.\left(\operatorname{LXXXIV}_{\mathrm{r}}\right)\right]$ Si quisiéredes saber quál es el camino malo que deve omne alexar, dize el sabio que mal ojo, otro dize que mal amigo, otro dize que mal vezino ${ }^{244}$

(101) No seas ligero de te ensañar, y ha contriçión un día antes de tu muerte, y cállate delant' los sabios, y aperçíbete de la inflamaçión d'ellos que su mordedura así como de lobo, y su ponçoña así como de escorpión, y su flama así como de bíbora, y todas sus palabras como ascuas de fuego ${ }^{245}$

(102) El mal ojo y la natura mala y el aborresçimiento de las gentes sacan el omne del mundo 246

(103) Sea el averío de tu próximo amado de ti, así como el tuyo mesmo, y estudía bien en la fee, ca no la puedes aver por herexía ${ }^{247}$

(104) Trabaja siempre de aprender la Ley por que sepas responder al que es hereje ${ }^{248}$

(105) Acata en tres cosas y no vernás a pecar: entiende de qué cosa vienes, y dónde vas, y delante de quién estás aparejado de ir a juizio 249

(106) Tres cosas son de gran peligro: el caminar de noche solo, y la vanidad de noche, y el pensar pensamientos vanos ${ }^{250}$

(107) Dar por amor de Dios limosna, da el omne de lo suyo de Dios; y por esto dixo David ${ }^{251}$ : «De ti señor es todo y de lo tuyo damos a ti» ${ }^{252}$

\footnotetext{
242 Pirqué Abot 2, 7

243 Pirqué Abot 2, 8

244 Pirqué Abot 2, 9

245 Pirqué Abot 2, 10

246 Pirqué Abot 2, 11

247 Pirqué Abot 2, 12

248 Pirqué Abot 2, 14

249 Pirqué Abot 3, 1

${ }^{250}$ Pirqué Abot 3, 4

251 Crónicas 29, 14

252 Pirqué Abot 3, 7
} 
(108) Todo aquel que el themor de su pecado es antes que su sabiduría es fuerte; todo aquel que su sabiduría adelanta el themor de su pecado no es su sabiduría fuerte 253

(109) $\left[82_{\mathrm{v}}\left(\operatorname{LXXXIV}_{\mathrm{v}}\right)\right]$ Todo aquel que sus fazimientos son menos que su sabiduría, su sabiduría es fuerte; todo aquel que sus fazimientos son más que su sabiduría non es fuerte. El dormir de la mañana y el vino de la siesta y el asentamiento de alegamiento de los que poco saben cabsan al omne pecado ${ }^{254}$

(110) Fundamiento de la sabiduría es callar ${ }^{255}$

(111) Todo aquel que su sabiduría es más que sus obras así es como el árbol, que sus raíces son muchas y sus ramas son pocas; y todo aquel que su sabiduría es menos que sus obras es así como el árbol, que sus fojas son muchas y las raíces son pocas, y viene el viento y arráncalo y fázelo caer; el otro es tal que, aunque venga todo el viento del mundo, non lo derriba ${ }^{256}$

(112) Quál es sabio, el que de todos aprende; aquél es barragán, el que se modera en tiempo de su saña 257

(113) Mejor es el que se apodera en su espíritu que el que gana çibdad. Y aquel es rico el que se contenta con lo que ha ${ }^{258}$

(114) Todo aquel que honra la fee y la ley es honrado, y todo aquel que despreçia la fee y la ley es menospresçiado, y meresçe morir muerte de erege 259

(115) El que se escusa del juizio quita de sí roido y enemistad y robo y juramento falso, y el que enduresçe su coraçón, el consejo es loco y malo y de cruel coraçón ${ }^{260}$

(116) $\left[83_{\mathrm{r}}\left(\operatorname{LXXXV}_{\mathrm{r}}\right)\right]$ Son tres coronas: la corona de buen cristiano y la corona de castidat y la corona de rey, pero la mejor es la corona de la buena fama ${ }^{261}$

(117) Faz el tu querer como el querer de tu amigo por que se faga tu querer así como su querer; priva lo que tú quieres por que él prive el querer de otros por el tu querer ${ }^{262}$

\footnotetext{
${ }^{253}$ Pirqué Abot 3, 9

254 Pirqué Abot 3, 10

255 Pirqué Abot 3, 13

256 Pirqué Abot 3, 17

257 Pirqué Abot 4, 1

258 Pirqué Abot 4, 1

259 Pirqué Abot 4, 1

260 Pirqué Abot 4, 7

261 Pirqué Abot 4, 13

262 Pirqué Abot 4, 12
} 
(118) Non nos da nada la sabiduría de los malos ni la disçiplina de los jus$\operatorname{tos} 263$

(119) No te atrevas en tu entendimiento 264

(120) Sed de aquellos que adelantan a salvar a todo omne, y sed cola para los leones, y non cabeçera para los raposos 265

(121) Mejor es vivir sola ora con contriçión y buenas obras en este mundo, que toda la vida del otro mundo; y mejor es una sola ora de gloria en el otro mundo, que toda la vida d'este mundo ${ }^{266}$

(122) No ruegues a tu amigo en la ora de su saña, ni lo conortes en la ora que su muerte está delant' del tendido, ni le demandes alguna cosa en la ora de su boto, ni fagas mucho por lo ver en el tiempo de su desonra ${ }^{267}$

(123) Si te echare en vergüença tu compañero la poridad de otrie, no le descubras por que no te eche en vergüença otra y la tu fama no sea buelta 268

(124) Manzanas de oro guarnidas de plata es la palabra dicha en su lugar ${ }^{269}$

(125) Argolla de oro y devisa preçiada es el castigo de sabio a la oreja que lo escucha 270

(126) Con el alongamiento de la ira se vençe grand prínçipe, y la lengua blanda quiebra el hueso 271

(127) $\left[83_{\mathrm{v}}\left(\mathrm{LXXXV}_{\mathrm{v}}\right)\right]$ Quando la miel fallares come lo que te cumple porque si te fartares avrás que gormar ${ }^{272}$

(128) Devieda el tu pie de la casa de tu amigo porque se enojará de ti y aborreçerte ha ${ }^{273}$

(129) Lança y espada y saeta aguda es el varón que responde contra su compañero testimonio falso 274

(130) Segund la dentera a los dientes y la tropeçadura al pie, así es la confiança del malo en día de tribulaçión ${ }^{275}$

(131) El que empeña la ropa en día de frío y el que canta con coraçón triste con estormentos es así como vinagre sobre greda 276

\footnotetext{
263 Pirqué Abot 4, 15

264 Pirqué Abot 4, 14

265 Pirqué Abot 4, 15

266 Pirqué Abot 4, 17

267 Pirqué Abot 4, 18

268 Proverbios, 25, 9-10

269 Proverbios, 25, 12

270 Proverbios, 25, 12

271 Proverbios, 25, 15

272 Proverbios, 25, 16

273 Proverbios, 25, 17

274 Proverbios, 25, 18

275 Proverbios, 25, 19

276 Proverbios, 25, 20
} 
(132) Si oviere fambre el tu malquerient' dale a comer del pan, y si oviere sed dale a bever del agua, ca çentellas pones sobre la tu cabeça y Dios te lo pechará 277

(133) Más vale estar sobr'el ala del tejado que non con muger barajosa y fechizera ${ }^{278}$

(134) No respondas al loco a su locura por que no seades su igual 279

(135) Responde al loco segund su locura por que no se tenga por sabio en sus ojos 280

(136) Si vieres omne que se tiene por sabio en sus ojos, más confiança ay en un loco que en él 281

(137) El que fuerça a los menesterosos es como la luvia rauda que no aprovecha 282

(138) Los que desmamparan la ley loan al malo y los que guardan ley combaten con ellos 283

(139) $\left[84_{\mathrm{r}}\left(\mathrm{LXXXVI}_{\mathrm{r}}\right)\right]$ Los omnes malos no entienden el derecho ${ }^{284}$

(140) Los que buscan a Dios entienden todo 285

(141) Más vale ser pobre y andar en sanidad que duro de costumbres y ser rico $^{286}$

(142) El que guarda la ley es fijo entendido y el que acompaña a los tragones envergüença a su padre ${ }^{287}$

(143) El que aparta su oreja de oir ley, la su oraçión es aborresçida ${ }^{288}$

(144) Bienaventurado es el omne que siempre ha themor, y el que enduresçe su coraçón sobr'él cahe su mal ${ }^{289}$

(145) El que labra su tierra fártase de pan y el que usa con los vazíos fártase de probredad 290

(146) El omne de fianças es de mucha bendiçión, y el que es quexoso por riqueza no puede ser limpio ${ }^{291}$

\footnotetext{
277 Proverbios, 25, 21-22

278 Proverbios, 25, 24

279 Proverbios, 26, 4

280 Proverbios, 26, 5

281 Proverbios, 26, 12

282 Proverbios, 28, 3

283 Proverbios, 28, 4

284 Proverbios, 28, 5

285 Proverbios, 28, 5

286 Proverbios, 28, 6

287 Proverbios, 28, 7

288 Proverbios, 28, 9

289 Proverbios, 28, 14

290 Proverbios, 28, 19

291 Proverbios, 28, 20
} 
(147) Quéxase por la riqueza el varón de mal ojo y non entiende que era de venir a mengua ${ }^{292}$

(148) El que castiga al omne después alcança graçia más qu'el lisonjero de lengua 293

(149) El que roba a su padre y a su madre y dize non fago pecado es igual del omne dañador ${ }^{294}$

(150) El que ha furioso el escudo rebuelve roido; y el que ha confiança en Dios es deleitoso; el que se confía con coraçón es loco; el que anda con saber aquél escapa ${ }^{295}$

(151) El que da al pobre no avrá mengua, y los que alçan sus ojos han muchas vistas 296

(152) Con el alçamiento del malo se esconde el omne y con la su prisión multiplican los justos 297

(153) $\left[84_{\mathrm{v}}\left(\mathrm{LXXXVI}_{\mathrm{v}}\right)\right]$ El varón que muchas vezes lo castigan es duro de çerviz $^{298}$

(154) Con los muchos justos se alegra el pueblo 299

(155) Con el apoderamiento del malo entristeze el pueblo ${ }^{300}$

(156) El varón que amare saber alegra a su padre con ilusión ${ }^{301}$

\footnotetext{
292 Proverbios, 28, 22

293 Proverbios, 28, 23

${ }^{294}$ Proverbios, 28, 24

295 Proverbios, 28, 25-26

296 Proverbios, 28, 27

297 Proverbios, 28, 28

298 Proverbios, 29, 1

299 Proverbios, 29, 2

300 Proverbios, 29, 2

301 Proverbios, 29, 3
} 